\title{
Study on the Law and Mechanism of Strata Movement Induced by Caving Mining of Slowly Inclined Large and Thick Orebody
}

\section{Chao Zhang}

University of science and technology Beijing https://orcid.org/0000-0002-4112-1939

\section{Mingchao Kang}

University of science and technology beijing

Jianxin Fu ( $\square$ fujun0011@126.com )

University of science and technology Beijing

Weidong Song

University of science and technology Beijing

\section{Research Article}

Keywords: Slowly inclined large and thick orebody, Caving mining, Strata movement, Surface collaps, Cantilever beam

Posted Date: April 29th, 2021

DOI: https://doi.org/10.21203/rs.3.rs-439914/v1

License: (9) This work is licensed under a Creative Commons Attribution 4.0 International License. Read Full License 


\section{Abstract}

Taking the Western District of Chengchao Iron Mine as engineering background, based on the GPS monitoring data of 8 years and the record of the surface movement, the law of strata subsidence and movement is studied. The studies have shown that the surface movement caused by underground mining has the characteristics of time delay and displacement angle development has the law of jumping. The strata movement caused by mining is divided into the stage of overlying strata collapse and the collapse stage of surrounding rock to goaf. In the first stage, the vertical stress plays a leading role and rock failure is shown as a regular barrel collapse. In the second stage, horizontal tectonic stress plays a leading role and the collapse mechanism of rock strata can be explained by the cantilever beam theory. According to the mechanism of strata movement analysis, strata movement of Chengchao Iron is divided into six regions, which respectively included vertical subsidence area, toppling sliding zone, dumping area, deformation zone, cumulative deformation area and undisturbed zone. The results of this paper can provide a theoretical basis for the surface movement prediction of caving mining in similar metal mine.

\section{Highlights}

- The caving method of slowly inclined large and thick orebody has the characteristics of delay and jump to the surface movement.

- The vertical stress plays a leading role before the surface collapse and the horizontal tectonic stress plays a leading role after the strata movement.

- The strata movement is divided into six zones, which respectively included vertical subsidence area, toppling sliding zone, dumping area, deformation zone, cumulative deformation area and undisturbed zone.

\section{Introduction}

The surface deformation caused by underground ore mining is a complex and changeable process, which is related to many factors. No matter what mining method is used and what the geological conditions are, the collapse and movement of rock strata are directly related to the surface deformation ${ }^{[1-2]}$. Therefore, it is of great significance to master the laws of rock collapse and movement. At present, abundant achievements have been made in the study of surface movement in coal mining ${ }^{[3]}$. Behrooz $\mathrm{G}$ et al ${ }^{[4-5]}$ used several sand-gypsum physical models to study the subsidence characteristics of multiple coal seams. The proposed subsidence characteristics of multiple coal seams can be used in the subsidence prediction method, and reliable prediction results are obtained. Zhang XS et al[ ${ }^{[6]}$ established physical and numerical models of longwall mining subsidence within a geotechnical setting, and obtained the deformation law of overburden through physical model test and numerical simulation. Cheng GW et al[ ${ }^{[7-8]}$ believed that the failure of the key stratum would caused the caved and fractured zones extend upward in the overburden and then surface cracks increase significantly. Zhao ${ }^{[9]}$ considered the surface 
deformation in the three stages of virgin state before mining, stage immediately after mine and flooding phase, and studied the surface deformation law caused by coal seam mining with numerical simulation. According to the formation mechanism of stepped subsidence, Ju JF et al ${ }^{[10]}$ deduced that the coal seam would be destroyed into a stable hinge structure after mining, leading to continuous subsidence containing only cracks, rather than step subsidence, and then explained the surface collapse. However, due to the characteristics of different ore-forming regularity, irregular orebody shape and significant influence of in-situ stress, the laws of rock collapse and movement in the gently inclined and thick orebody metal mines mined by caving method are different from those of coal mines dominated by sedimentary rocks ${ }^{[11]}$.

The Chengchao Iron Mine, one of the most famous underground metal mines in China, has been mining by sublevel caving method without sill pillar. So far, serious surface subsidence has occurred in the East and west areas of Chengchao Iron Mine, which has seriously affected the normal production of the mine. Over the years, many scholars have studied it and achieved a lot of valuable research results ${ }^{[12-16]}$. Lei $\mathrm{YK}^{[17]}$ took pillar mining as the research object and analyzed the influence of four pillar mining schemes on surface stability through numerical simulation. Deng $Y Y^{[18-20]}$ and Xia KZ et al ${ }^{[21-22]}$ systematically analysed the causes of surface collapse in Chengchao Iron Mine, mainly analysing the size and extension range of surface deformation caused by ore-body mining. Song WD ${ }^{[23-24]}$ preliminarily revealed the basic rules of roof surrounding rock caving mechanism and surface subsidence in the mining process of sublevel caving without pillar in metal mines.

In addition, regarding the surface collapse caused by similar mine caving methods. Ma FS and Ding K et $\mathrm{al}^{[25-26]}$ took the surface movement caused by filling mining in Jinchuan Nickel Mine in China as an example to analyze, and combined with geological survey and ground monitoring, the ground movement and deformation and failure were mainly analyzed. Zhang $\mathrm{P}^{[27]}$ used numerical simulation to analyze the stability of the subsidence area and put forward the corresponding treatment plan with the Beiminghe Iron Mine as the background. Guo YH ${ }^{[28-31]}$ took Shizishan Copper Mine as the research background, discussed the rock mass movement law, deformation, failure mechanism and deformation prediction related problems in the mining of steeply inclined metal orebody in high stress area. Taking Jinshan Iron Mine as the research background, $\mathrm{Ma} \mathrm{J}^{[32]}$ studied the movement and change rules of backfilling body in surface collapse pits through the combination of laboratory tests and numerical simulation, and formulated a reasonable backfilling process. $\mathrm{Xu} \mathrm{SH}^{[33]}$ took Dahongshan Iron Mine as the research background, studied the development law of Dahongshan collapse pit and rock movement, and planned to treat the collapse pit by means of backfilling.

But at present, the research on the law of strata collapse and movement caused by underground mining in metal mines is still insufficient, especially for the gently inclined thick orebody. Therefore, the law of strata movement is still unclear, the law of surface collapse and deformation mechanism need to be further studied. To sum up, based on the surface deformation monitoring data and macro damage phenomenon in the west area of Chengchao Iron Mine in recent 8 years, this paper analyzes and studies 
the laws of strata collapse and movement induced by caving mining, and probes into the mechanism of surface collapse and expansion.

\section{Chengchao Iron Mine Introduction}

\subsection{General situation of engineering geology}

Chengchao Iron Mine is an important production base of iron ore and pellet ore of Wuhan Iron and Steel Group Company, and it's also a famous large-scale underground iron mine in China.

Chengchao mining area is located in the west of the lower Yangtze depression, between Huaiyang shield and Jiangnan ancient land. It belongs to the west wing of the frontal arc of Huaiyang epsilon structure. The mining area is adjacent to the East-West structural belt with Mufushan as the main body in the south, Liangzi Lake depression with Neocathaysian structure in the West and South Huaiyang fault in the north, As shown in Fig. 1. There are mainly two structural systems in Echeng area, one is the Huaiyang epsilon structure (the southeast section of the west wing of frontal arc), and the other is the Neocathaysian structure. Among them, the epsilon structure is the main structure in this area, which determines the general outline of the regional structure and the general direction of the distribution of intrusions and iron deposits.

In the area of Chengchao iron ore deposit, there are two groups of structural features. One is NWW, and the other is NNE. The structure in the mining area is complex. There are both NWW trending Huaiyang epsilon structure and NNE trending Neocathaysian structure. They overlap each other in space and alternate with each other in time, forming a complex and orderly structural pattern. Among them, the NWW trending epsilon structure is the main structure in the mining area, which controls the distribution of strata, the occurrence of rock mass and distribution of skarn and iron ore bodies.

Chengchao mining area contains sedimentary rocks, magmatic rocks and metamorphic rocks. Anhydrite deposits are distributed near the contact zone between marble and granite; iron ores are distributed near the contact zone between diorite and granite; skarns are distributed near the contact zone between hornfels and granites, they are in the shape of pulse and lens.

There are four groups of structural planes of granite body in the footwall of orebody, and the directions of structural planes are NE, NWW, NNW and NEE. The footwall joints are mainly compression shear joints with flat and smooth joint surface with long extension. Among them, the NE trending joints are the most developed and tend to the southeast. They are developed through the surface and the exposed parts of underground roadways. The maximum visible extension length can reach $50 \mathrm{~m}$, and the joint density is about 10 joints / $\mathrm{m}$. The NWW trending joints are also the main joints of granite, and their strikes are consistent with the strike of orebody and Chengchao fault. The development degree of the joints is almost the same as the NE trending joints. On the surface, the NWW trending joints incline to SSW with steep dip angle; on the underground roadway, the NWW trending joints incline to NNE with dip angle ranging from $44^{\circ}$ to $66^{\circ}$. The NWW trending joints are also developed in the surface and underground 
roadways, the joint density is about 3-8 joints / $\mathrm{m}$. The NEE trending joints are developed and mainly found in the survey points on the surface, the joint density is about 0.1-1.0 joints / $\mathrm{m}$.

The results of in-situ stress measurement show that the direction of the minimum principal stress is basically perpendicular to the strike of the orebody; the variation law of the depth of the intermediate principal stress is close to the vertical stress caused by the self weight of the rock mass; the direction of the maximum principal stress is $\mathrm{N} 85^{\circ}$ to $75^{\circ} \mathrm{W}$, which is basically consistent with the strike of the orebody. The main stress distribution diagram of Chengchao Iron Mine is shown in Fig. 2.

\subsection{Orebody occurrence and structure distribution}

Chengchao Iron Mine is divided into east and west mining areas, bounded by geological exploration line15. The 3D model is constructed as shown in Fig. 3.

There are many ore bodies in the mining area. The iron ore bodies mainly include I, II, III, IV, V, VI, VII, etc. The large-scale iron ores include II, III, VI and VII. On the plane, the iron ore bodies are generally distributed in parallel in the direction of NWW. On the longitudinal section, they are inclined to the north and west, as shown in Fig. 4. On the transverse section, the main iron ore bodies are also staggered from head to tail and partially overlapped. Most of the ore bodies occur in or near the contact zone of porphyry granite, leucodiorite and dolomitic marble. The orebodies are mostly irregular lenticular and gently inclined to the south. Some orebodies or ore sections often appear branching and compounding, expansion and contraction.

\subsection{Current status of exploitation}

The west area of Chengchao Iron Mine had been put into production since 2002, and the sublevel caving method without sill pillar was adopted for mining. The first mining level is $-290 \mathrm{~m}$, and the subsequent mining levels are $-307.5 m,-325 m,-342.5 m,-358 m$ and $-375.5 m$. The composite diagram above $-375.5 m$ level is shown in Fig. 5. The superimposed three-dimensional map of orebody mining area is shown in Fig. 6. The statistics of mining progress in the western area are shown in Table 1.

Table 1 Information of western exploitation 


\begin{tabular}{|c|c|c|c|}
\hline \multirow[t]{2}{*}{ Mining level/m } & \multicolumn{2}{|c|}{ Mining time (Year /Month) } & \multirow[t]{2}{*}{ Mined orebody } \\
\hline & Begin & End & \\
\hline-290 & $2002 / 07$ & $2004 / 07$ & 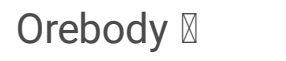 \\
\hline-307.5 & $2002 / 11$ & 2004/07 & Orebody $\otimes$ \\
\hline-325 & $2003 / 05$ & $2004 / 12$ & Orebody $\rrbracket$ \\
\hline-342.5 & $2004 / 07$ & $2006 / 12$ & Orebody $\rrbracket$ \\
\hline-358 & $2005 / 10$ & 2008/09 & Orebody $\otimes$ \\
\hline-375.5 & $2007 / 07$ & 2012/06 & Orebody $\otimes$ \\
\hline
\end{tabular}

\subsection{Introduction of surface subsidence}

The eastern area of Chengchao iron mine started mining from 16m in 1970, and the surface collapsed in 1971. So far, with the development of mining, the scope of surface collapse had been expanding. Since 2006, collapse pits, surface cracks and shaft cracks had appeared in the west area. On April 17, 2006, surface subsidence occurred in the east of Chengchao Bay. The subsidence area is located in the center of the surface subsidence deformation area (between line 37 and line 39), forming a subsidence pit with an area of $4140 \mathrm{~m}^{2}$. On April 18, in the east side of the subsidence deformation area, the surface collapse occurred again, with a collapse area of about $150 \mathrm{~m}^{2}$, as shown in Fig. 7. After the surface collapsed, the surface deformation in the western region is in a gradual deformation stage.

\section{Statistics And Analysis Of Surface Deformation Monitoring 3.1 Layout of deformation monitoring points}

In order to effectively grasp the deformation and collapse laws of surface and deep rock mass in the west area of Chengchao Iron Mine, monitoring was carried out in 2006. The monitoring contents mainly include: $₫$ surface displacement monitoring, the horizontal displacement and surface subsidence were monitored by GPS and level; $\nabla$ the deformation and collapse of deep rock mass were monitored. Among them, 131 surface GPS measuring points were mainly distributed in the footwall rock mass of the mining area. Rock deformation and collapse monitoring adopts borehole closed circuit method, as shown in Fig. 8.

Considering the selected deformation and collapse monitoring points and deep rock mass deformation monitoring points for the analysis in this paper, the applied monitoring points are identified, and the mining boundary and the location of main buildings (structures) are identified in combination with Fig. 5 , as shown in Fig. 9. 


\subsection{Analysis of surface deformation}

Based on the measured data of surface deformation from December 2007 to September 2013, the corresponding result map is drawn. The moving line distribution of the mining area is shown in Fig. 10 (The horizontal deformation of the ground surface $\varepsilon=2 \mathrm{~mm} / \mathrm{m}$ is taken as the moving boundary). It can be seen from the result maps that after September 2010, a sharp expansion took place in the direction of the new auxiliary shaft (the northeast).

The moving line expanded greatly at the south, the north and the northeast, and the maximum expansion at the northeast reached $290 \mathrm{~m}$; At this stage, for the key areas near the $2 \mathrm{~cm}$ displacement boundary line, such as beneficiation workshop, transportation tunnel, new auxiliary shaft and Shijiawan village, the cumulative deformation fluctuated with time (as shown in Fig. 11-14).

The cumulative deformation increases with time. The maximum horizontal deformation near the beneficiation workshop is $8 \mathrm{~cm}$, and the maximum sinking deformation is $14 \mathrm{~cm}$. The maximum horizontal deformation near the transportation tunnel is $120 \mathrm{~cm}$, and the maximum sinking deformation is $100 \mathrm{~cm}$. The maximum horizontal deformation near the new auxiliary shaft is $30 \mathrm{~cm}$, and the maximum sinking deformation is $20 \mathrm{~cm}$. The maximum horizontal deformation near Shijiawan village is $10 \mathrm{~cm}$, and the maximum sinking deformation is $20 \mathrm{~cm}$.

For more detailed analysis, three sections are selected to analyze the movement angle in detail, as shown in Fig. 15.

The movement angle changes of the three sections and their corresponding relationship with mining level are shown in Fig. 16.

There were skip shaft and new main shaft in the footwall of section I. Up to September 2013, the horizontal distance between the moving range and skip shaft was 138m. From December 2007 to September 2013 , the footwall movement range of section I expanded by $118 \mathrm{~m}$ in horizontal distance, the hanging wall movement range expanded by $119 \mathrm{~m}$ in horizontal distance. There was little difference in the development speed of hanging wall and footwall moving range.

There was a new auxiliary shaft in the footwall of section II, and the horizontal distance between the moving range of the section and the new auxiliary shaft was $17 \mathrm{~m}$ until September 2013. From December 2007 to September 2013, the footwall movement range of section II expanded by $188 \mathrm{~m}$ in horizontal distance, the hanging wall movement range expanded by $59 \mathrm{~m}$ in horizontal distance. The development speed of the hanging wall was obviously faster than that of the footwall.

The west end of section III was the beneficiation plants. By September 2013, the moving range of the section began to affect the buildings near the beneficiation workshop. However, the movement range of the west end of section III developed slowly. From December 2007 to September 2013, the movement range expanded $27 \mathrm{~m}$, and the movement angle was between $59^{\circ}$ and $57^{\circ}$. 
According to the monitoring results, the movement Angle results of each section were statistically analyzed, and the variation of the movement Angle of different goaf locations on different sections with time was drawn into a curve, as shown in Fig. 17-19. In summary and analysis, the following rules can be obtained:

(1) When the bottom of the goaf is fixed, the movement angle will decrease with time, and the change rate of the movement angle will decrease with time in a short time. In the first half of the year, the decrease range of the moving angle is the largest. As shown in Fig. 17(a), when the bottom of the goaf is at $-375 \mathrm{~m}$, the movement angle decreased by $4.54^{\circ}$ in the half year from December 2007 to June 2008, and the movement angle decreases by $2.12^{\circ}$ in the year after June 2008. In Fig. 17(b), when the bottom of the goaf is at $-360 \mathrm{~m}$, the movement angle decreased by $6.29^{\circ}$ from December 2008 to December 2009. From December 2009 to September 2013, the change of movement angle was only $3.5^{\circ}$.

(2) When the bottom of the goaf is fixed, the movement angle change may develop by leaps and bounds. As shown in Fig. 17(a), when the bottom of the goaf was at $-395 \mathrm{~m}$, the movement angle changed in the process of slow change - accelerated change - slow change - accelerated change.

As shown in Fig. 20(a), when the bottom of goaf in hanging wall of section I was at $-395 \mathrm{~m}$, the change rate of movement angle was $0.51^{\circ}$ / half year in June 2010; in the following year, it increased to $1.12^{\circ} /$ half year in June 2011 ; then it decreased to $0.30^{\circ}$ / half year in June 2012; in the following half year, the change rate of movement angle rapidly increased to $1.25^{\circ} /$ half year. The change rate of footwall movement angle of section I is shown in Fig. 20 (b), which shows a wave shape similar to Figure 26, and its variation period is about 2 years.

(3) The influence of underground mining on the surface is delayed. After the goaf reaches a new level, the movement range will not expand instantaneously, resulting in a sudden increase in the monitored movement angle and a rapid decrease in the following half a year.

\subsection{Analysis of strata movement law}

The horizontal deformation value and sinking deformation value of the rock mass around the mined-out area are calculated, and their ratios are calculated. The calculation shows that the horizontal deformation value of rock mass is larger than the sinking deformation value, and the rock mass mainly moves horizontally, and the ratio of the horizontal deformation value to the sinking deformation value is different with the increase of the distance from the goaf.

Select section $\otimes$ draw level of footwall rock mass deformation and sinking deformation ratio distribution, as shown in Fig. 21. With the increase of the distance from the goaf, the ratio of horizontal deformation and sinking deformation of the profile first increases, reaching 2.48 at the measuring point E03, and then decreases gradually. As the stress caused by mining sinking and the stress caused by topography overlap 
in the same direction, the deformation value in the downhill direction is greater than that in the flat, especially the horizontal movement value.

Considering the deformation of the measuring point LG2 in the downhill direction and the measuring point E04 on the ground, the cumulative horizontal deformation and sinking deformation curves of the two points are drawn, as shown in Fig. 22.

From the plane, the plane distance between LG2 and goaf is $142 \mathrm{~m}$, while the plane distance between E04 and goaf is $134 \mathrm{~m}$. Theoretically, the deformation value of E04 should be larger than that of LG2, which is true in the early mining stage. However, from the horizontal displacement, by October 2008, the horizontal displacement value of LG2 began to be greater than the horizontal deformation value of E04. As of April 2012 , the horizontal deformation of LG2 is $293.1 \mathrm{~cm}$, while the horizontal deformation of E04 is $192.8 \mathrm{~cm}$, with a difference of about $100.3 \mathrm{~m}$. The reason for this situation is that in the early stage of mining, the unbalanced movement of the area where E04 and LG2 are located is small, and no cracks are generated on the surface. After that, with the expansion of the horizontal and vertical range of the goaf, the unbalanced movement value of the area where the measuring point E04 and LG2 are located is larger due to underground mining, resulting in cracks on the surface. At this time, the horizontal stress caused by the terrain in the downhill direction is released. The superposition of horizontal tensile stress of mining subsidence and terrain characteristics makes the horizontal movement value along with the downhill direction increase, and the increment is related to slope shape, relative position of goaf and structural plane character. However, the sinking value of LG2 began to be larger than that of E04 after March 2011. This is because when the horizontal displacement deformation value increases to a certain extent, the rock mass in the downhill direction will be destroyed, so the sinking value in the downhill direction will begin to increase at this time.

\subsection{Analysis of deep rock mass deformation and collapse}

Monitoring is carried out through two monitoring holes ZK1 and ZK2. The monitoring time is 17 months from the completion of the monitoring drilling to the end of the surface caving in the western area, and the monitoring interval is 1 month. Abundant and accurate data are obtained through observation. The caving process of rock mass is shown in Fig. 23.

Combined with the construction process of the observation holes and underground production situation, the roof caving process has the following three characteristics:

(1) During the period of caving, the roof did not appear to fall. With the mining progress in the lower section, after the goaf appeared at the top of the stope, the surrounding rock of the roof gradually fell to the upper part.

(2) Before the surface collapse, the falling speed is very slow or no falling occurs for a long time. When it is about to collapse, larger height of surrounding rock suddenly falls. The ground surface collapsed on 
April 17, 2006. From March 3 to April 14, ZG1 hole collapsed by 20m and ZG2 hole collapsed by 60m. However, ZG1 hole did not collapse during the period from October 7, 2005, to March 6, 2006, while ZG2 hole collapsed by 10m during the period from October 7, 2005, to March 3, 2006.

(3) The failure and caving of roof rock develop upward intermittently and abruptly. From the results of borehole monitoring, it can be concluded that the upward development of roof surrounding rock is not uniform but has obvious jumping characteristics. For example, the caving height time curve obtained from ZG1 hole has a very obvious step shape, which shows a process of slow caving (caving stop) $\rightarrow$ sudden caving $\rightarrow$ slow caving (caving stop) $\rightarrow$ sudden caving $\rightarrow$ surface collapse.

Combined with the observation results of the two boreholes, the caving process of the roof can be obtained, as shown in Fig. 24. It can be seen from the figure that the first mining level of the west end of orebody is higher than the east end of orebody, and the caving time is much earlier than that of orebody. Therefore, a small caving arch is formed at the west end first, and with the mining of the lower east end of orebody, the roof caving gradually shifts eastward, thus forming a larger range of caving arch.

\section{Analysis And Discussion On Mechanism Of Strata Movement}

The strata movement caused by underground mining is a process advancing with time, so the strata movement mechanism caused by mining is different in different stages. According to the investigation data of surface monitoring and macroscopic damage, the strata movement and deformation in the west area of Chengchao Iron Mine can be divided into two stages: before and after the appearance of surface collapse pits. The first stage is the stage of surface collapse, which caused by the overburden above the goaf is destroyed and extended to the surface; the second stage is the expanding stage of collapse area after the collapse pit appears.

In order to analyze the mechanism of strata movement in the west area of Chengchao Iron Mine, we can establish a typical geological model of Chengchao Iron Mine by combining engineering geological profile of the mining area perpendicular to orebody and the field investigation of joints (Fig. 25).

\subsection{The stage of the overburden failure in goaf extends to surface collapse}

In the initial stage of underground mining, with mining development, the goaf is gradually expanded. At this time, a small amount of rock in the upper part of the goaf will collapse under the action of gravity, and then the rock at the top of the goaf will form an arch under the action of horizontal tectonic stress, forming the supporting vault of the goaf. The supporting vault can ensure the stability of the upper rock mass temporarily, and the surface will not produce obvious deformation and failure.

With the continuous expansion of goaf in plane and depth, the pressure arch effect becomes more and more obvious, and the arch span becomes larger and larger. However, the span of the arch must adapt to 
the properties of the arch materials. When the span increases to a certain extent and the rock mass at the top of the goaf can not form a supporting vault, the rock mass at the top will become unstable and will gradually collapse into the goaf. After a large enough goaf is formed by underground mining, the collapse will gradually increase and eventually transfer to the surface, forming a collapse pit on the surface. The specific process is generally shown in Fig. 26. According to Fig. 22, the caving process of the western roof also conforms to the general law.

The main factors that affect the rate of overburden collapse are as follows:

(1) Scope and height of goaf: As of April 2006, the cumulative vertical height of mining in the west area of Chengchao Iron Mine is about $52.5 \mathrm{~m}$, the average mining depth of orebody is $412.5 \mathrm{~m}$, and the ratio of mining depth to cumulative vertical height is 7.9. Bai $\mathrm{YR}^{[34]}$ and others ${ }^{[35-36]}$ analyzed the law of surface subsidence and strata movement caused by underground mining in the eastern area of Chengchao Iron Mine and considered that when the ratio of mining depth to mining cumulative vertical height is less than 17, strata movement will affect the surface; otherwise, it will not affect the surface. According to Bai YR's conclusion, the mining thickness ratio in the west area of Chengchao Iron Mine has already reached the influence range in 2006. Therefore, it is reasonable that the west area of Chengchao Iron Mine collapsed suddenly in April 2006.

(2) Quality of overlying strata: At this stage, if the rock mass quality at the top of the goaf is not good enough, the collapse may develop rapidly. The main lithology of goaf overburden in the west area is gypsum, diorite and marble, and the lithology quality is average. The average karstification rate of marble is $1.30 \%$ from 0 to $-150 \mathrm{~m}$ elevation. The investigation of rock mass structural planes shows that there are a large number of joints in gypsum, diorite and marble, and the overall orientation of the joints is disordered and the shape is irregular. There are many types of overlying strata in the western goaf, which naturally forms the soft layer of rock strata contact surface with steep dip Angle. Thus it can be seen that the overall quality of overlying rock mass in the western goaf is poor.

(3) Groundwater drainage: On the one hand, in the process of underground mining, the goaf cuts off the direct connection between overburden water system to water system in the rock mass below, which increases the effective stress in the overlying strata; on the other hand, due to the groundwater drainage, the hydrodynamic pressure in the overlying strata increases.

(4) Horizontal tectonic stress in the mining area: There is a large horizontal tectonic stress in Chengchao Iron Mine. After the formation of goaf, the horizontal tectonic stress will be concentrated in the overlying strata, which will promote the collapse of overburden with disordered joint distribution.

In addition, the horizontal tectonic stress increases the abutment pressure of surrounding rock on both sides of the goaf and increases with the increase of the scope of the goaf. At this time, the mechanism of the maximum horizontal stress on the surrounding rock can be simplified to the form of fixed pillars at both ends, which is called the "rock pillar" failure mode of surrounding rock, The "rock pillar" of 
surrounding rock is composed of one structure or several structures. Its mechanical model and bending moment diagram are shown in Fig. 27.

Before the overlying strata fracture and collapse, the overlying strata and rock pillars only have bending deformation, so the deformation transferred to the surface is very small, and there is no crack on the surface. According to the mechanical model of rock pillar, the "pillar" around goaf becomes the bearing body of horizontal tectonic stress in surrounding rock. With the increase of the height of goaf, the horizontal stress on the "pillar" becomes larger and larger, and then it begins to deform and produce tensile stress on the "pillar". When the tensile stress in the "pillar" reaches the allowable tensile strength or the horizontal stress reaches the shear strength, the "pillar" begins to collapse(Fig. 28). After the "pillar" near the goaf is destroyed, another "pillar" in the outer layer begins to bear the horizontal tectonic stress in the surrounding rock. The damaged "pillar" and the roof caving rock can protect the "pillar" in the outer layer and lead to the reduction or disappearance of the "pillar" effect. It can be seen that the " pillar " effect caused by the large horizontal tectonic stress in the mining area increases the scope of underground goaf and is also one of the reasons for large surface movement and subsidence.

In a word, the appearance of surface collapse in the west area of Chengchao Iron Mine is the inevitable result because of underground mining, and the collapse range is affected by horizontal tectonic stress and overburden inclination, which exceeds the prediction in footwall and end.

\subsection{The outward expansion stage of collapse area}

When the surface collapse pit appears, the surface collapse deformation begins to enter the expansion stage of collapse range. After the collapse area is formed, horizontal tectonic stress release will lead to tensile deformation of the surrounding rock of the collapse pit and tensional fracture to the collapse area. The rock with tensional fracture will collapse under the action of gravity. In this paper, the mechanical mechanism of cantilever beam is used to analyze the deformation of footwall rock mass in the west area of Chengchao Iron Mine.

The NE and NWW trending steep joints in the footwall granite of the Western District play a major role in the deformation and cracking of the rock mass. The joint cuts the footwall into a cantilever beam model. The stress diagram of the first cantilever beam closest to the collapse failure area is shown in Fig. 29.

Before the collapse of the surface, the surrounding rock arm of the overburden caving range is in force balance state in the horizontal direction (as shown in Fig. 29 (a)). There will be no horizontal deformation. After the collapse pit appears on the surface and enters the second deformation stage, the rock in the collapse area becomes a nearly granular structure due to caving. The horizontal stress exerted on the surrounding rock arm begins to decrease (as shown in Fig. 29 (b)). Because of the unbalanced force in the horizontal direction, the rock arms begin to tilt to the goaf. After the rock arm closest to the collapse area tilt to a certain extent, the horizontal stress on the outer rock arm also began to decrease, so that the outer rock arm also begin to tilt to the goaf due to the unbalanced force. Therefore, the range of 
surface deformation is gradually extended. When the horizontal toppling deformation of the rock arm reaches a certain degree, and the internal tensile stress reaches the allowable tensile strength or the horizontal stress reaches the shear strength, the rock arm will break (as shown in Fig. 29 (c)).

Several factors affect the deformation range of surface subsidence at this stage:

(1) Scope of goafs: After the surface collapse, the scope of underground goafs continues to expand in depth and plane, which makes the scope of surface collapse continue to expand. The rock arms in the expanding range of goafs will produce vertical subsidence under the action of gravity, and their outer rock arm will continue to transfer deformation outward due to unbalanced force. It can be seen that the range of goafs, especially the range of plane expansion, play a decisive role in the range of surface movement and subsidence.

(2) Characteristics of surrounding rock: There are four groups of structural planes in the footwall granite of the orebody in the western area, which are NE, NWW, NNW and NEE. The structural plane with steep dip angle cuts the footwall granite into steep rock pillar, so there is the above mode of the bending failure transfer of cantilever beam of surrounding rock makes the surface collapse and deformation. The occurrence of structural plane in surrounding rock also determines the distribution characteristics of surface fractures.

(3) Tectonic stress in the mining area: there is a large horizontal tectonic stress field in the mining area. The maximum principal stress along the orebody strike direction is only 1.28 times of the gravity, and the horizontal stress perpendicular to the orebody strike direction is 0.48 times of the vertical stress. The horizontal stress is the driving force of surrounding rock deformation and has an important impact on the surface movement and subsidence.

In the first stage of strata movement mentioned above, the gradual increase of underground goaf scope in the horizontal and vertical direction will cause the surface deformation and collapse. But the surface deformation is still in a certain range and has not been transferred to the range far away from the goafs, as shown in Fig. 30 (a). At this stage, underground mining is the main reason of surface deformation, and gravity is the main driving force of surface collapse.

After the strata move into the second stage, under the action of the release and compression of the horizontal tectonic stress, i.e., the maximum principal stress $\mathrm{GX}$, which is parallel to the orebody strike, the rock mass around the collapse pit, which is divided into columnar shape by faults and joints, begins to produce arch expansion deformation towards the goaf and collapse pit. At the same time, the release of horizontal tectonic stress GY, which is perpendicular to the orebody strike, causes the rock mass to produce unloading tensile fracture deformation in the collapse direction. The combined action of the two directions of tectonic stress makes the columnar surrounding rock collapse (as shown in Fig. 30 (b)). So far, the extension of the surface deformation range has entered the tectonic stress leading stage. After the surface deformation enters into the tectonic stress leading stage, the surface deformation in the relevant areas within the deformation range is mainly horizontal movement, and the vertical displacement is

Page 13/39 
relatively small. However, the dip angle of columnar structure rock mass in this area decreases with time, and the ratio of surface vertical displacement to horizontal displacement begins to increase. From the spatial point of view, the closer to the goaf, the larger the ratio of vertical displacement to horizontal displacement, and vice versa. Thus, the funnel-shaped deformation curve is formed on the surface.

\subsection{Page and line numbers}

According to the above analysis of strata movement mechanism, based on the deformation state of rock mass, the strata are divided into six areas, as shown in Fig. 31.

(1) Vertical subsidence area: The area is located above the goaf, which is mainly formed in the first stage of strata movement and expands with the expansion of underground goaf.

(2) Toppling slip area: The area is the range of collapse and fracture of rock pillar around the collapse pit after the formation of vertical subsidence area. In this area, after the cantilever beams around the vertical collapse area topple to a certain extent and break, the rock pillars begin to slide to the goafs. Therefore, the deep rock mass in this area should have obvious slip surface, and its deformation mode is sliding and toppling, and staggered open cracks are formed on the surface. Some areas of powder ore storage yard and mining area highway belong to this area. No matter the horizontal displacement or vertical displacement of the surface in this area is large, they can reach several meters. There is usually a large width crack or obvious fracture in this area, as shown in Fig. 32 and Fig. 33.

(3) Toppling area: Because of the toppling and sliding of the front rock pillars, the rock pillars in this area also toppled, but their interiors were not broken. Therefore, the deformation mode of rock mass in this area is mainly toppling, and the area forms open cracks on the surface, which is the main area of surface crack expansion. Part of the transport tunnel belongs to this area. The surface deformation in this area is large, which can reach tens of centimeters. The surface deformation is mainly horizontal displacement, and the ratio of horizontal displacement to vertical displacement is much larger than this value of the toppling slip area. There are usually wide through cracks in the toppling area, such as the cracks in the transport tunnel in Fig. 34. The outer boundary of the area corresponds to the boundary of the surface subsidence range.

(4) Deformation area: Due to horizontal stress release, the rock mass in this area also has a certain toppling deformation. However, due to the small deformation, only small cracks are formed on the ground. In this area, the surface deformation is mainly horizontal deformation, the ratio of horizontal displacement to vertical displacement is further increased. The deformation area is also the production area of cracks, with a certain number of microcracks. The outer boundary of the area corresponds to the boundary of the surface movement range.

(5) Deformation accumulation area: The area is located at the outermost edge of the influence range of surface deformation. Although the rock mass in this area is also affected by the underground goafs, the 
influence is very small, and the horizontal displacement and vertical displacement of the rock mass deformation are not obvious. There is no obvious surface feature either in the deep or on the surface.

(6) Undisturbed area: Because the rock mass outside the deformation area is not affected by underground mining, it can be called undisturbed area.

The six areas of deep rock mass will continue to expand downward and around with mining development.

\section{Conclusion}

Based on the GPS monitoring data and on-site fracture records of the west area of Chengchao Iron Mine in recent 8 years, the laws of strata collapse and movement during mining are studied, the conclusions are as follows:

(1) The underground mining influence on surface movement is delayed, and movement angle development is jumping. When the mining depth is fixed, the movement angle will decrease with the time delay, and the reduction rate in a short time will also decrease; When working at the same level for a long time, the decrease rate of the movement angle will not decrease continuously, but present jumping, showing a cycle process of slow change - accelerated change - slow change - accelerated change.

(2) The strata movement caused by underground mining can be divided into two stages: the first stage is the collapse stage of goaf overlying strata; the second stage is the toppling failure stage of surrounding rock around the goafs. In the first stage, the vertical stress plays a leading role, which shows regular bucket collapse. In the second stage, the horizontal tectonic stress plays a leading role, which can be expressed by the mechanical structure of cantilever beam.

(3) According to the analysis of the strata movement mechanism, the strata movement of Chengchao Iron Mine can be divided into six areas: vertical subsidence area, toppling slip area, toppling area, deformation area, deformation accumulation area and undisturbed area.

(4) The research results of this paper can provide a basis for the prediction of surface movement law of similar metal mines with thick orebody mined by caving method.

\section{Declarations}

\section{Declaraction of Competing Interest}

The authors declare that they have no known competing financial interests or personal relationships that could have appeared to influence the work reported in this paper. 


\section{Acknowledgments}

This experimental work was financially supported by the National Natural Science Foundation of China (Grant No. 51974012), National Natural Science Foundation of China Youth Fund (51804016), Fundamental Research Fund for the Central Universities (FRF-TP-19-014A3) for financial support.

\section{References}

1. Brown ET. Block Caving Geomechanics. Brisbane:Julius Kruttschnitt Mineral Research Centre, 2003

2. Charlie $C$.Disturbance of mining operations to a deep underground workshopn. Tunneling Underground Space Technol, 2006, 21 ( 1): 1.

3. Qian MG, Miao XX® Theory research of critical layer in strata control. Journal of China Coal Society, 1996, 21 ( 3) : 225-230.

4. Behrooz G, Gang R, John V.S. Characterising the multi-seam subsidence due to varying mining configuration, insights from physical modelling. International Journal of Rock Mechanics and Mining Sciences, 93(2017)269-279.

5. Behrooz G, Gang R, James B, et al. A predicative methodology for multi-seam mining induced subsidence. International Journal of Rock Mechanics and Mining Sciences, 93(2017)280-294.

6. Zhang XS, Yu HC, Dong JY, et al. A physical and numerical model-based research on the subsidence features of overlying strata caused by coal mining in Henan, China. Environmental Earth Sciences, 2017, 76:705.

7. Cheng GW, Yang TH, Liu HY, et al. Characteristics of stratum movement induced by downward longwall mining activities in middle-distance multi-seam. International Journal of Rock Mechanics and Mining Sciences, 136(2020)104517.

8. Cheng GW, Chen CX, Li LC, et al. Numerical modelling of strata movement at footwall induced by underground mining. International Journal of Rock Mechanics and Mining Sciences, 108(2018)142156.

9. Zhao J, Konietzky H. Numerical analysis and prediction of ground surface movement induced by coal mining and subsequent groundwater flooding. International Journal of Coal Geology, 229(2020)103565.

10. Ju JF, Xu JL. Surface stepped subsidence related to top-coal caving longwall mining of extremely thick coal seam under shallow cover. International Journal of Rock Mechanics and Mining Sciences, 78(2015)27-35.

11. Wang FT, Zhang C, Zhang XG. Overlying strata movement rules and safety mining technology for the shallow depth seam proximity beneath a room mining goaf. International Journal of Mining Science and Technology, 2015, 25(1): 139-143.

12. Song XG, Chen CX, Xia KZ, et al. Analysis of the surface deformation characteristics and strata movement mechanism in the main shaft area of Chengchao Iron Mine. Environmental Earth Science, 
2018, 77:335.

13. Cheng GW, Chen $\mathrm{CX}$, Ma TH, et al. A case study on the strata movement mechanism and surface deformation regulation in Chengchao underground Iron Mine. Rock Mechanics and Rock Engineering, 2017(50): 1011-1032.

14. Cheng GW, Chen CX, Li LC, et al. Numerical modelling of strata movement at footwall inducedby underground mining. International Journal of Rock Mechanics and Mining Sciences, 108(2018)142156.

15. Huang PL. Study of influence of discontinuities on rock movement and surface deformation in eastern area of Chengchao iron mine. Rock and Soil Mechanics, 2011.

16. Pang HS, Chen $\mathrm{CX}$, Xia KZ, et al. A methodology based on strain analysis for identifying potential discontinuous deformation zones in sublevel caving mines. Engineering Geology, 297(2020)105872.

17. Lei YL. Surface deformation law and concentrating mill stability due to the excavation of the orepillar in Chengchao Iron Mine. Metal Mine(China), 2018(07): 25-31.

18. Deng YY, Chen CX, Xia KZ, et al. Cause analysis of surface collapse in western area of Chengchao Iron Mine. Rock and Soil Mechanics, 2019, 40(02): 743-758.

19. Deng YY, Chen CX, Xia KZ, et al. Ground movement and deformation caused by underground mining in eastern area of Chengchao Iron Mine. Rock and Soil Mechanics, 2018, 39(09): 3385-3394.

20. Deng YY, Chen CX, Xia KZ, et al. Investigation on the distribution characteristics of ground cracks in the Chengchao Iron Mine, China. Environmrntal Earth Sciences, 2019, 78: 280.

21. Xia KZ, Chen CX, Deng YY, et al. In situ monitoring and analysis of the mining-induced deep ground movement in a metal mine. International Journal of Rock Mechanics and Mining Sciences, 109(2018)32-51.

22. Xia KZ, Chen CX, Zheng Y, et al. Engineering geology and ground collapse mechanism in the Chengchao Iron Mine in China. Engineering Geology, 249(2019)129-147.

23. Song WD, Du JH, Yin XP, et al. Caving mechanism of hanging wall rock and rules of surface subsidence due to no-pillar sub-level caving method in an iron mine. Journal of China Coal Society, 2010, 35(07): 1078-1083.

24. Song WD, Wang X, Du JH. Surface deformation law of Chengchao Iron Mine induced by pillarless sublevel caving mining method. Metal Mine, 2012, (07): 9-12+18.

25. Ma FS, Zhao HJ, Yuan RM, et al. Ground movement resulting from underground backfill mining in a nickel mine (Gansu Province, China). Natural Hazards, 2015(77), 1475-1490.

26. Ding K, Ma FS, Zhao HJ, et al. Investigation of the mechanism of roof caving in the Jinchuan Nickel Mine, China. Rock Mechanics and Rock Engineering, 2018(51), 1215-1226.

27. Zhang P. Study on the stability of surface subsidence in Beiminghe Iron Mine. North China University of Science and Technology, 2020.

28. Guo YH. Study regularity $\llbracket$ mechanism and deformation forecast of rockmass movement induced bu caving mining steep deposit in high stress area. Kunming University of Science and Technology, 
2015.

29. Guo YH, Hou KP. Stability on goaf of a large thick steeply inclined deposit with continuous caving mining. Electronic Journal of Geotechnical Engineering, 19(2014), 6399-6411.

30. Guo YH, Hou KP. Study on surface subsidence law induced by deep mining of large steep metal deposit. Applied Mechanics and Materials, 295-298(2013), 2902-20905.

31. Guo YH, Hou KP. Numerical simulation of ground surface settlement induced by open-cut subway station. Applied Mechanics and Materials, 522-524(2014), 2902-2905.

32. Ma J. Investigation on backfilling body movement law of the subsided area and backfilling measures of Jinshandian Iron. Wuhan University of Science and Technology, 2012.

33. Xu SH. Backfilling treatment scheme of the surface subsidence pit of Dahongshan Iron Mine. Modern Mining(China), 2016, 32(03): 179-181.

34. Bai YR, Gu ZM, Bai SW. Primary study on ground surface subsidence and rock mass movement in east area of Chengchao Iron Mine due to underground mining. Chinese Journal of Rock Mechanics and Engineering, ,2002(03): 340-342.

35. Chen LL, Chen CX, Xia BR, et al. Study on the mechanism of formation and expansion of ground caving-in in the eastern Chengchao Iron Mine. Rock and Soil Mechanics, 2017, 38(08): 2322-2334.

36. Zhang KX, Wang P, Pei MS, et al. Study on the surface subsidence based on combined mining of deep orebody in Chengchao Iron Mine. Metal Mine(China), 2016(01): 171-175.

\section{Figures}

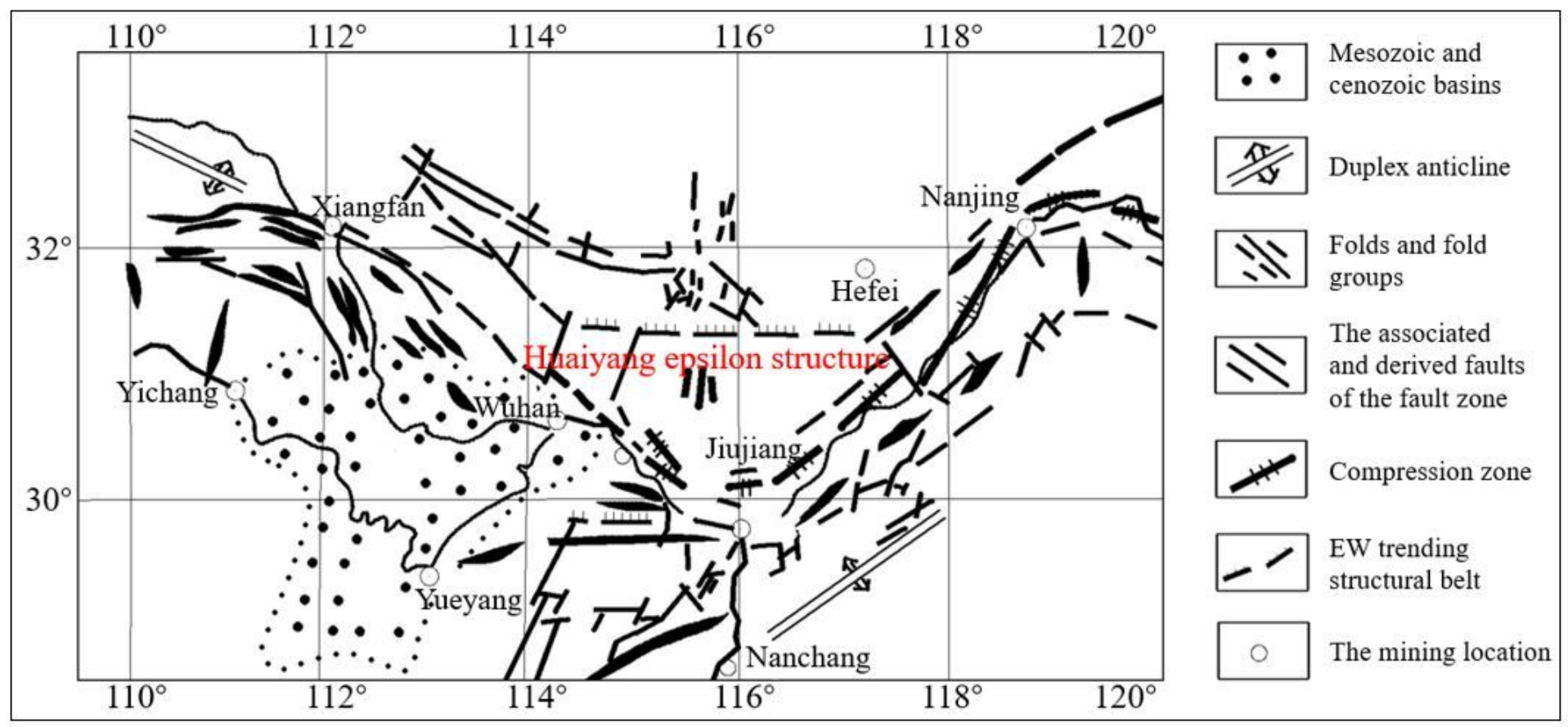

Figure 1 
Position diagram of Huaiyang epsilon structure in the mining area

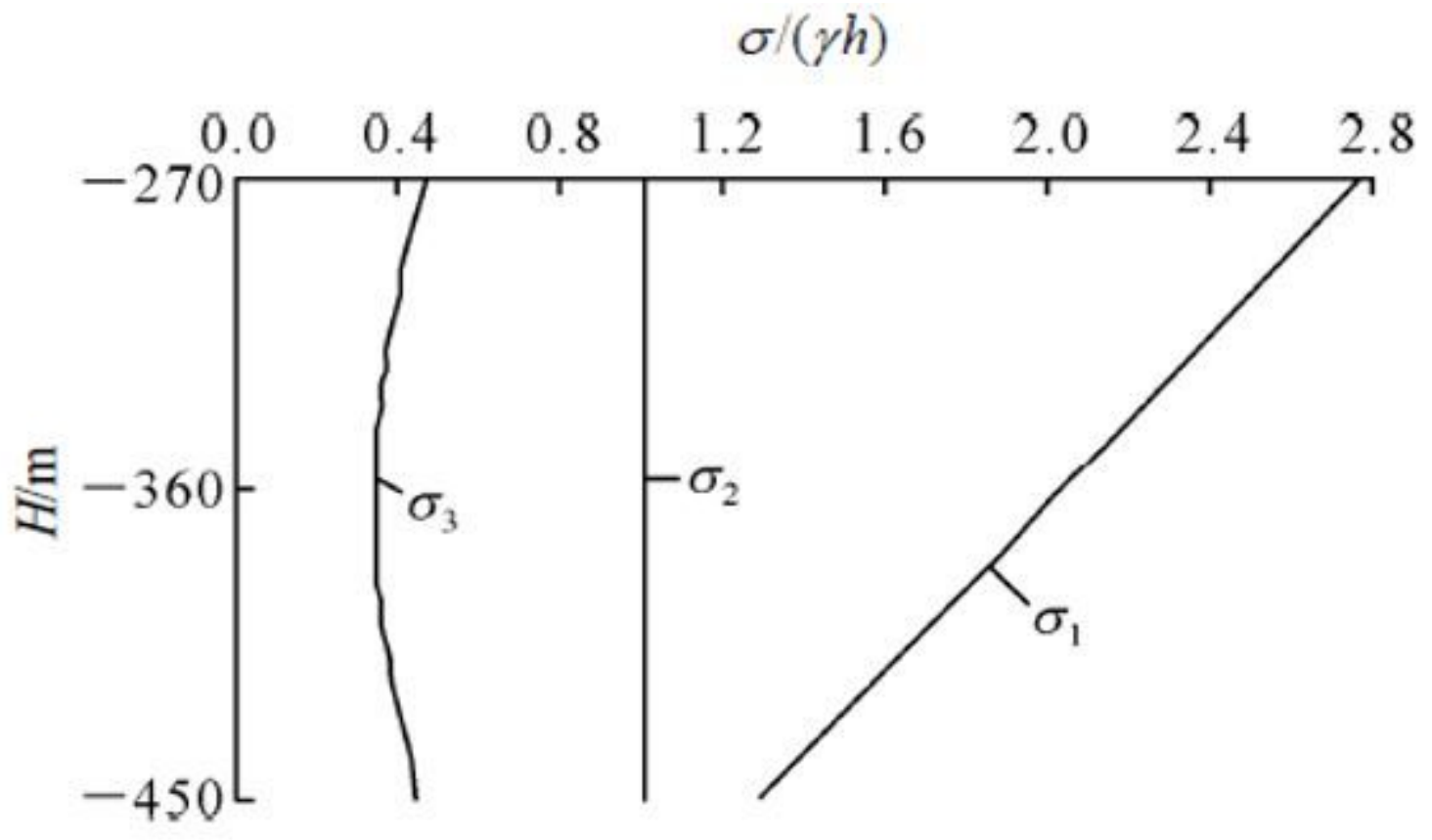

Figure 2

Sketch of principal stress distribution of Chengchao Iron Mine

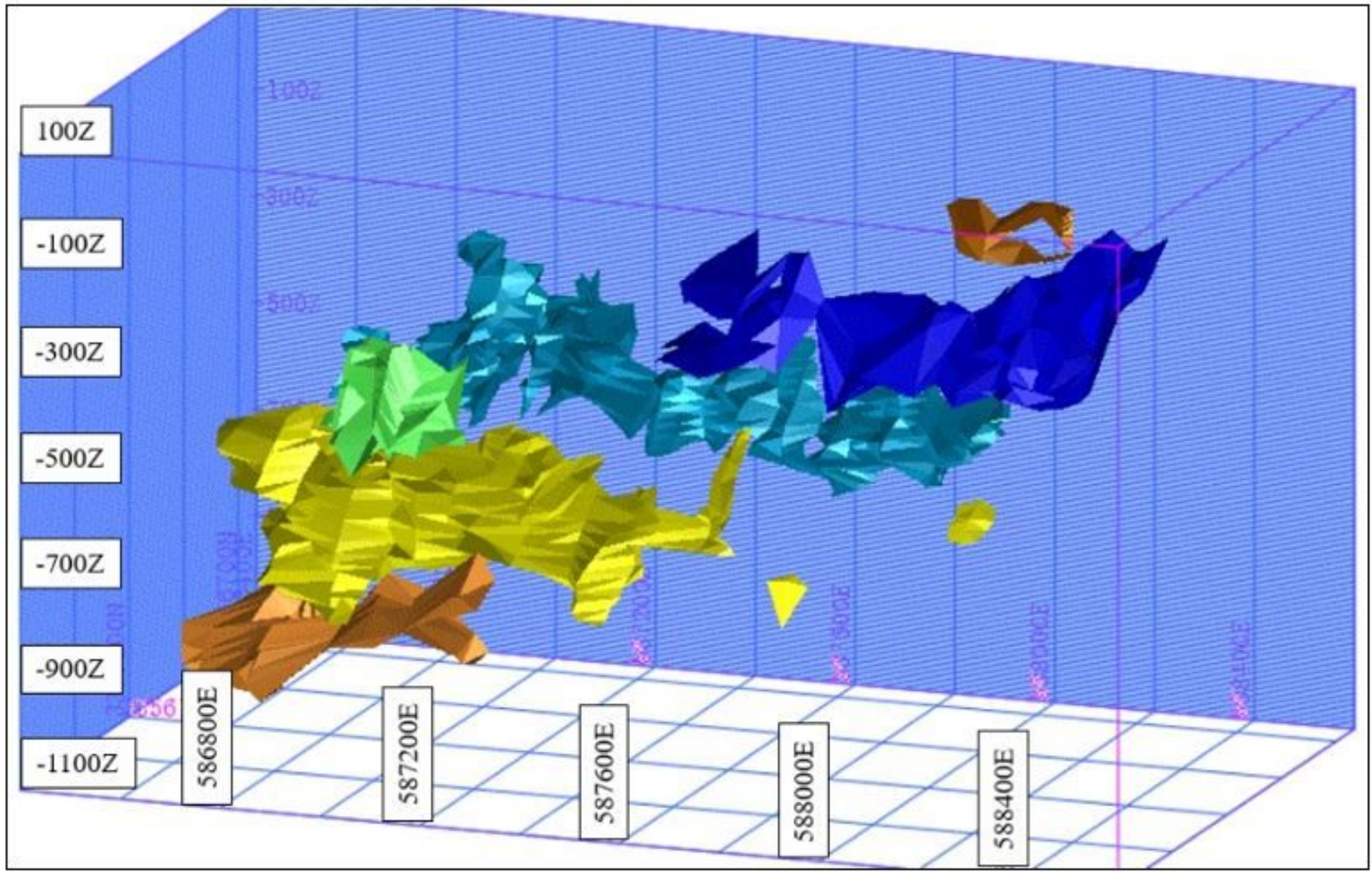


Figure 3

3D model of the main orebody in Chengchao Iron Mine

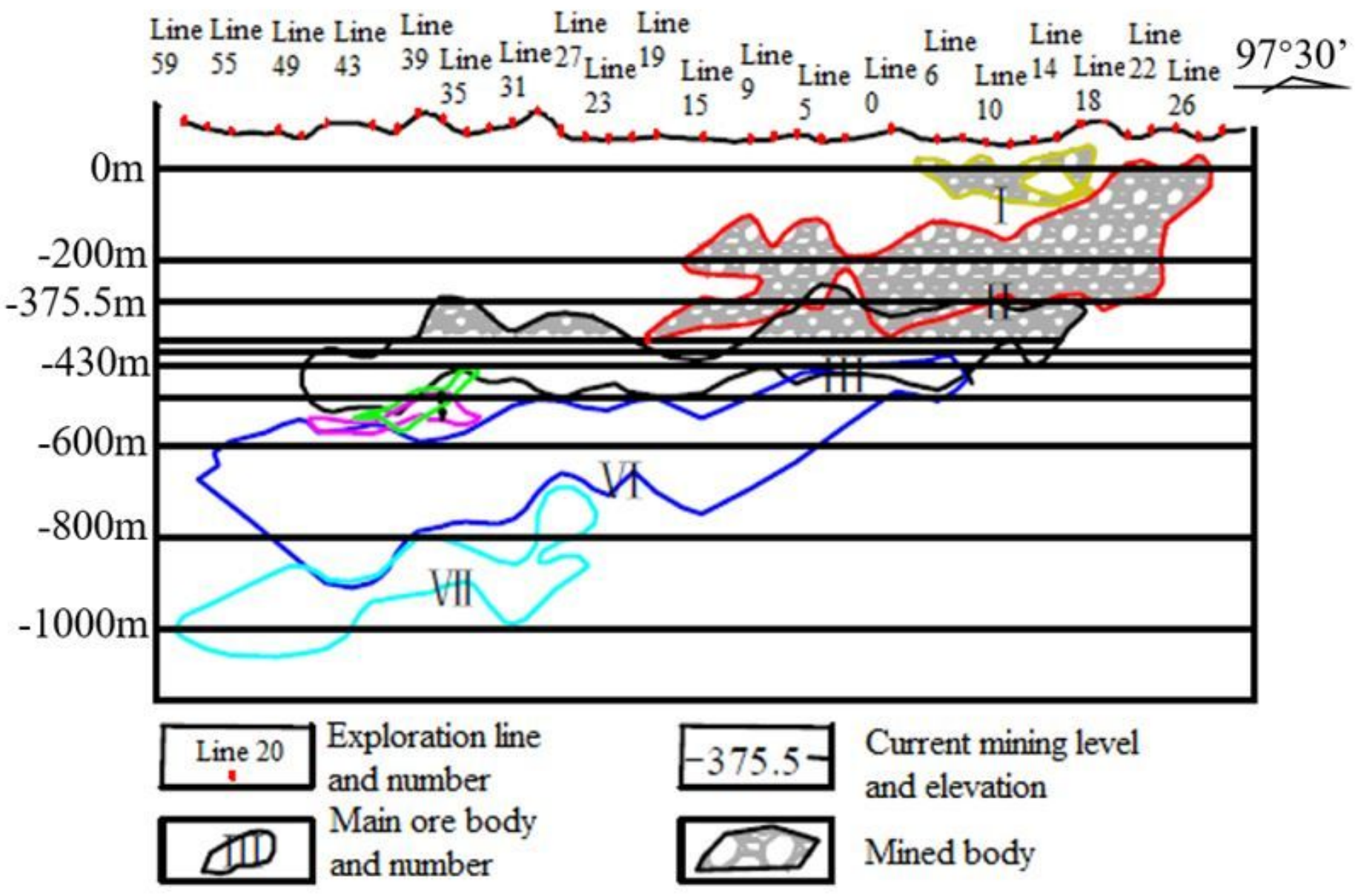

Figure 4

Projection of the main orebody 


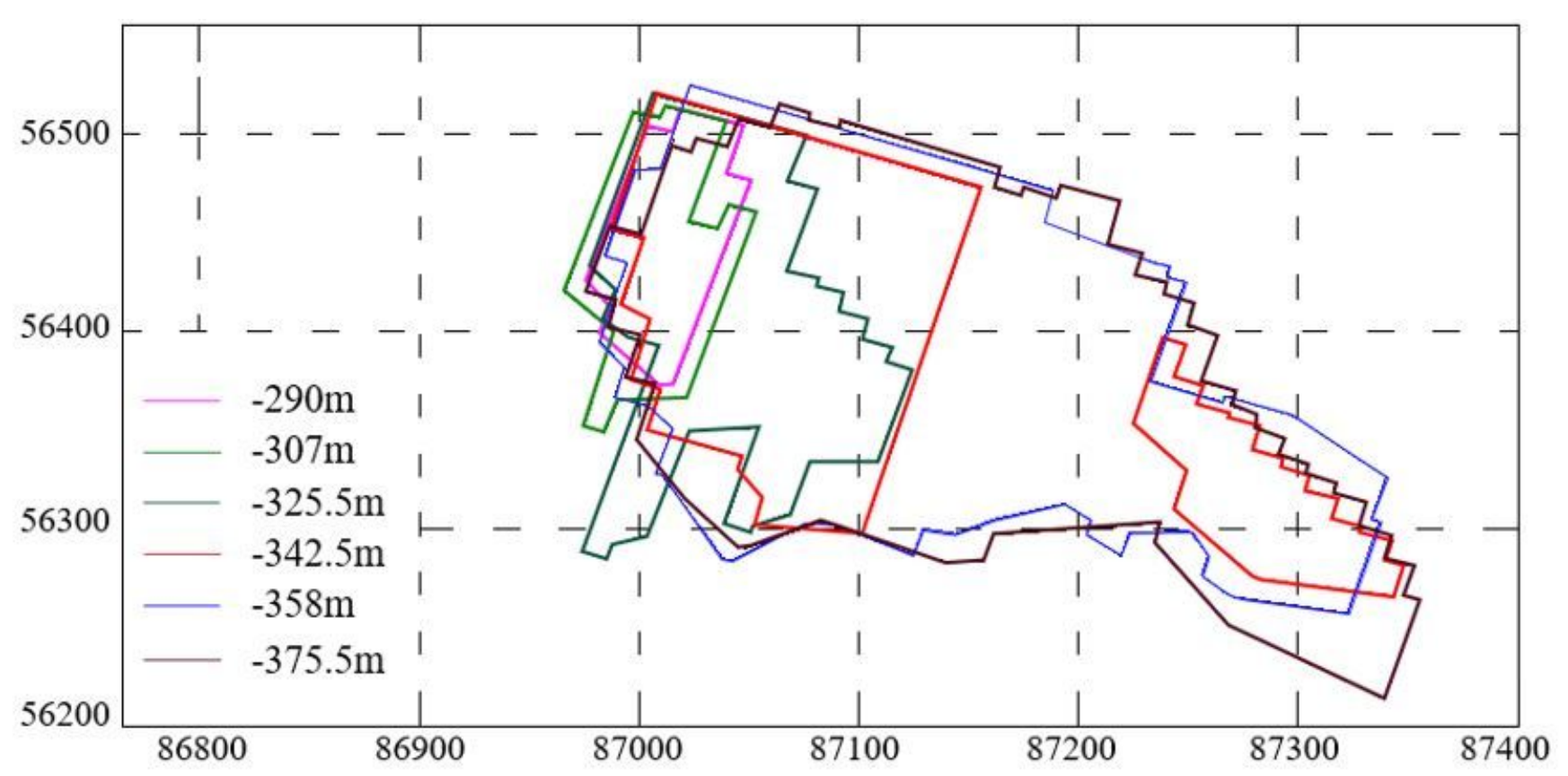

\section{Figure 5}

Chart of Mining progress of above $-375 \mathrm{~m}$ level

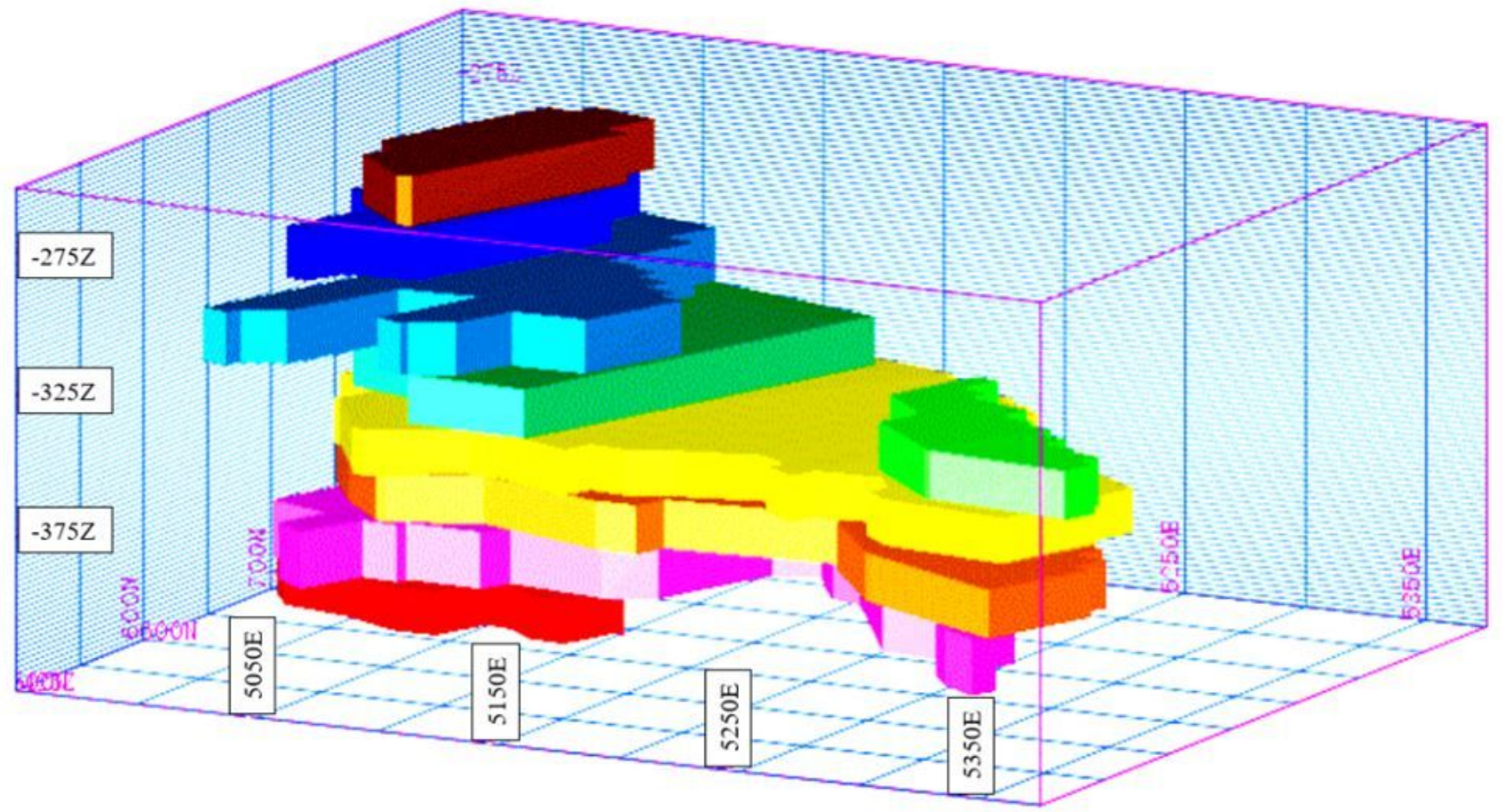

Figure 6

Superimposed 3D map of orebody mining area 


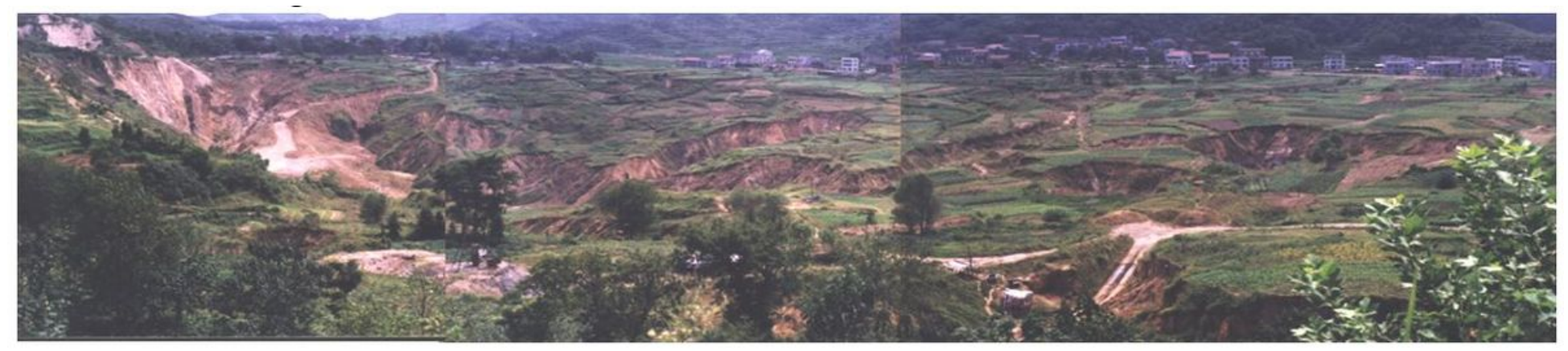

Figure 7

Panorama of collapse area

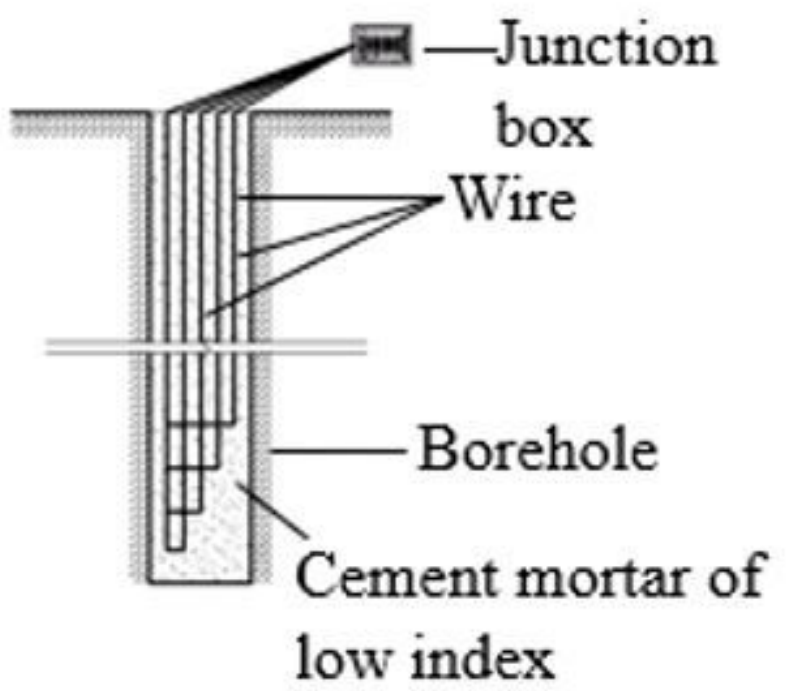

Figure 8

Schematic of detecting holes and wire 


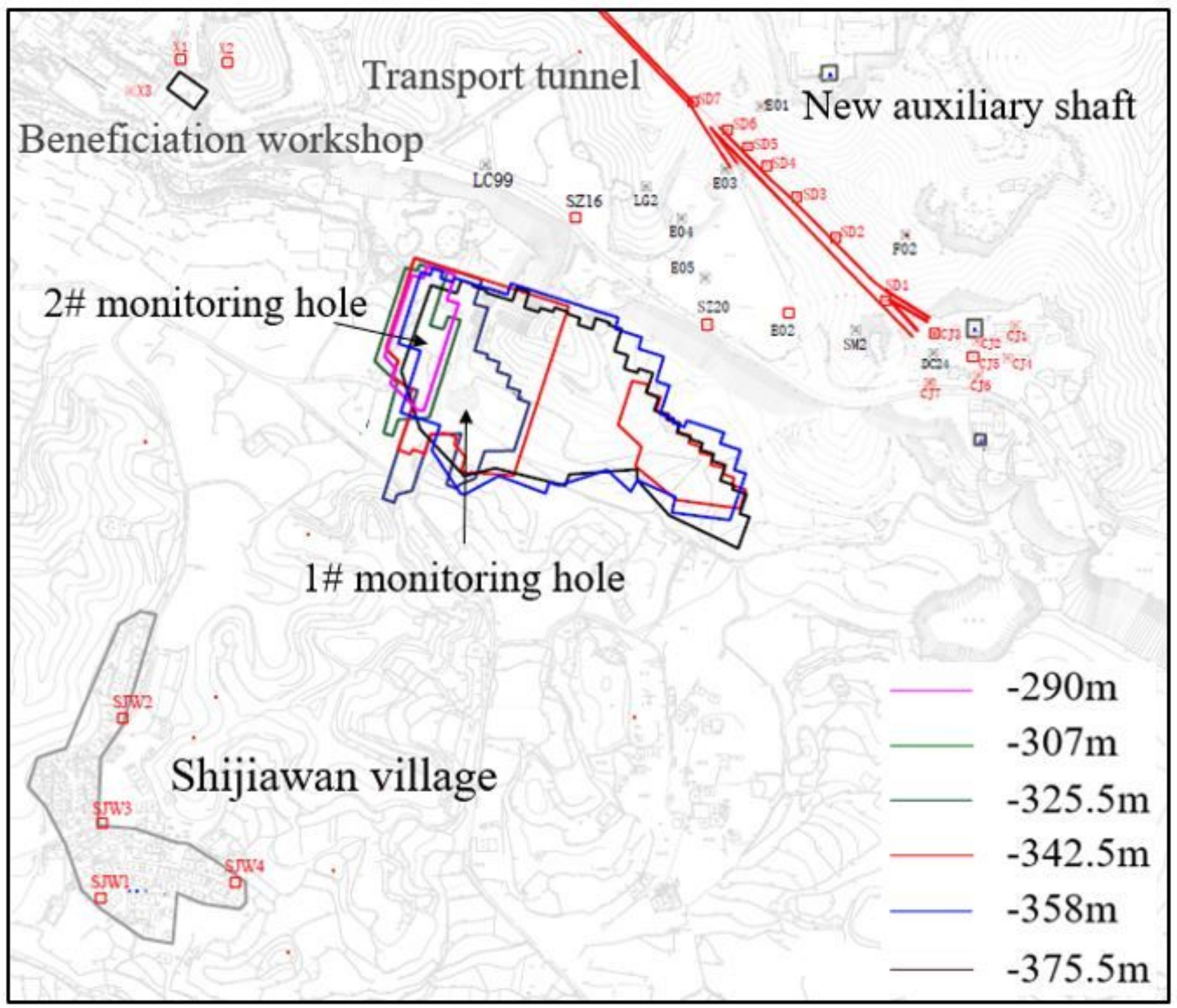

Figure 9

Layout of monitoring points 


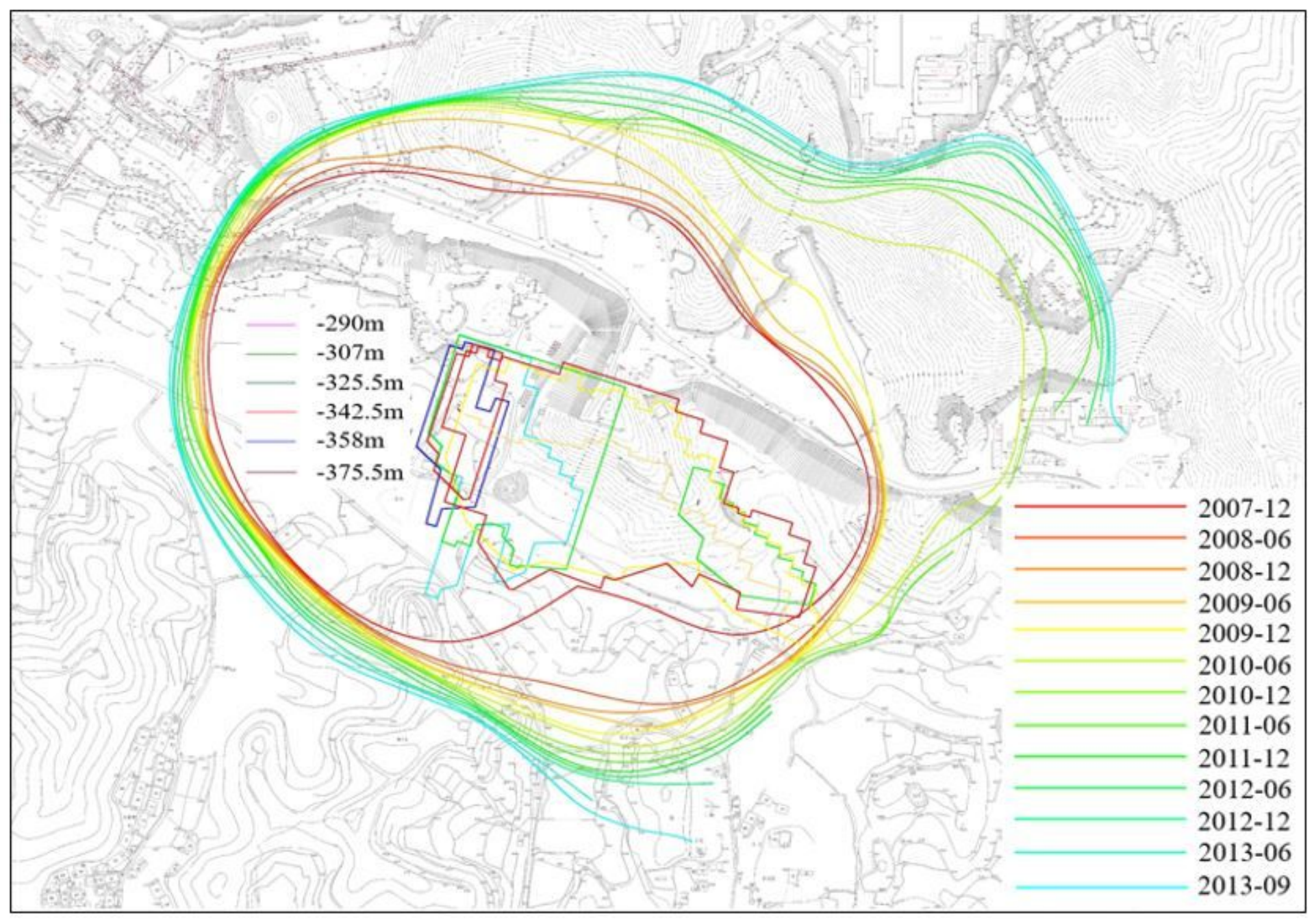

Figure 10

Distribution of moving line from 2007 to 2013

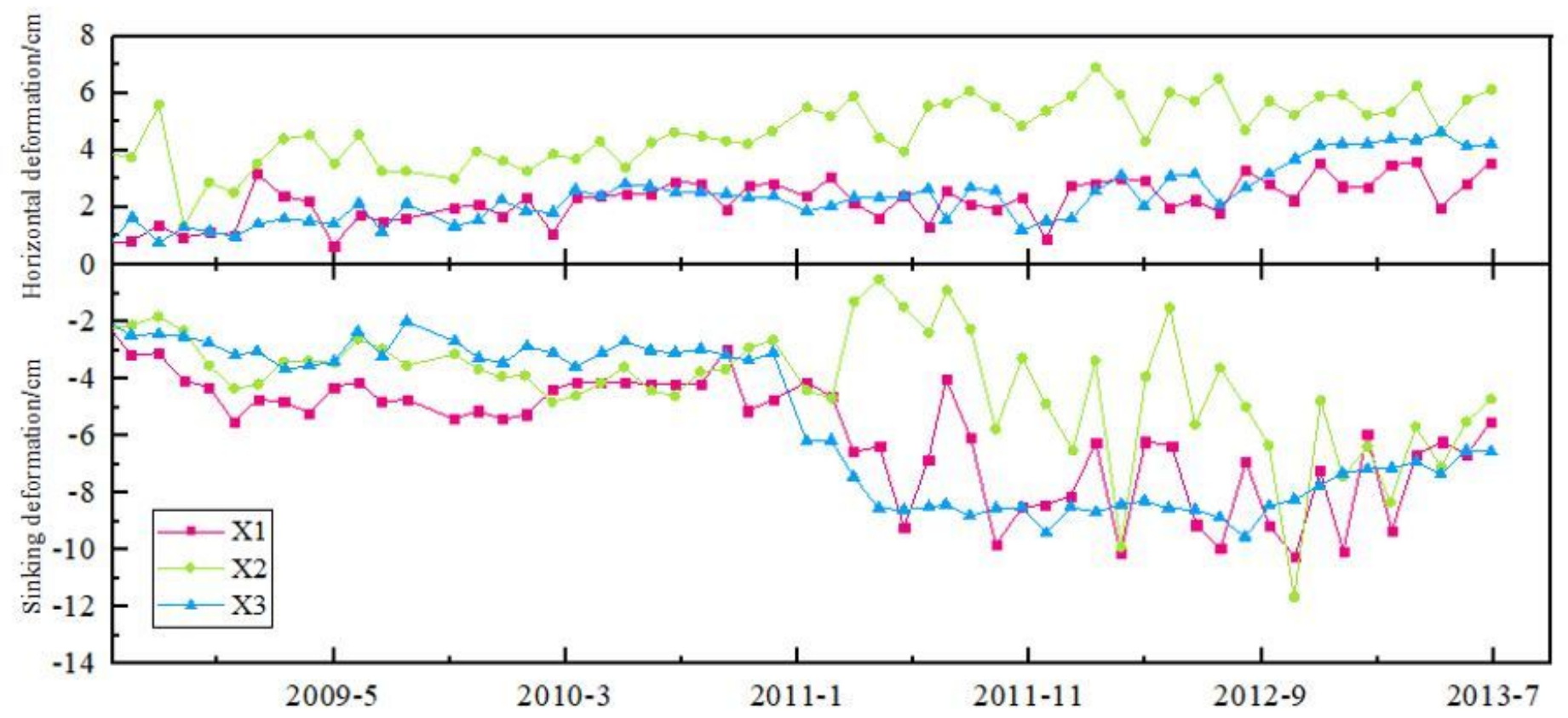




\section{Figure 11}

Cumulative deformation map of measuring points near beneficiation workshop

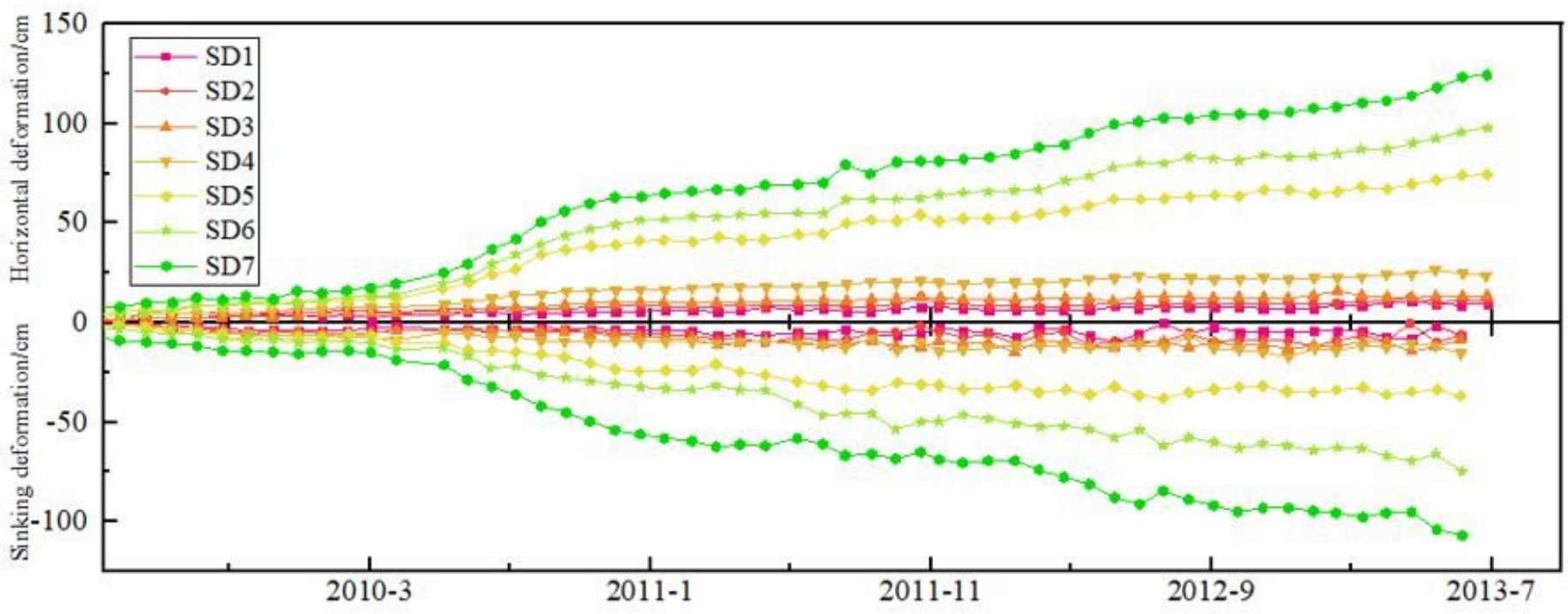

Figure 12

Cumulative deformation map of measuring points near transport tunnel

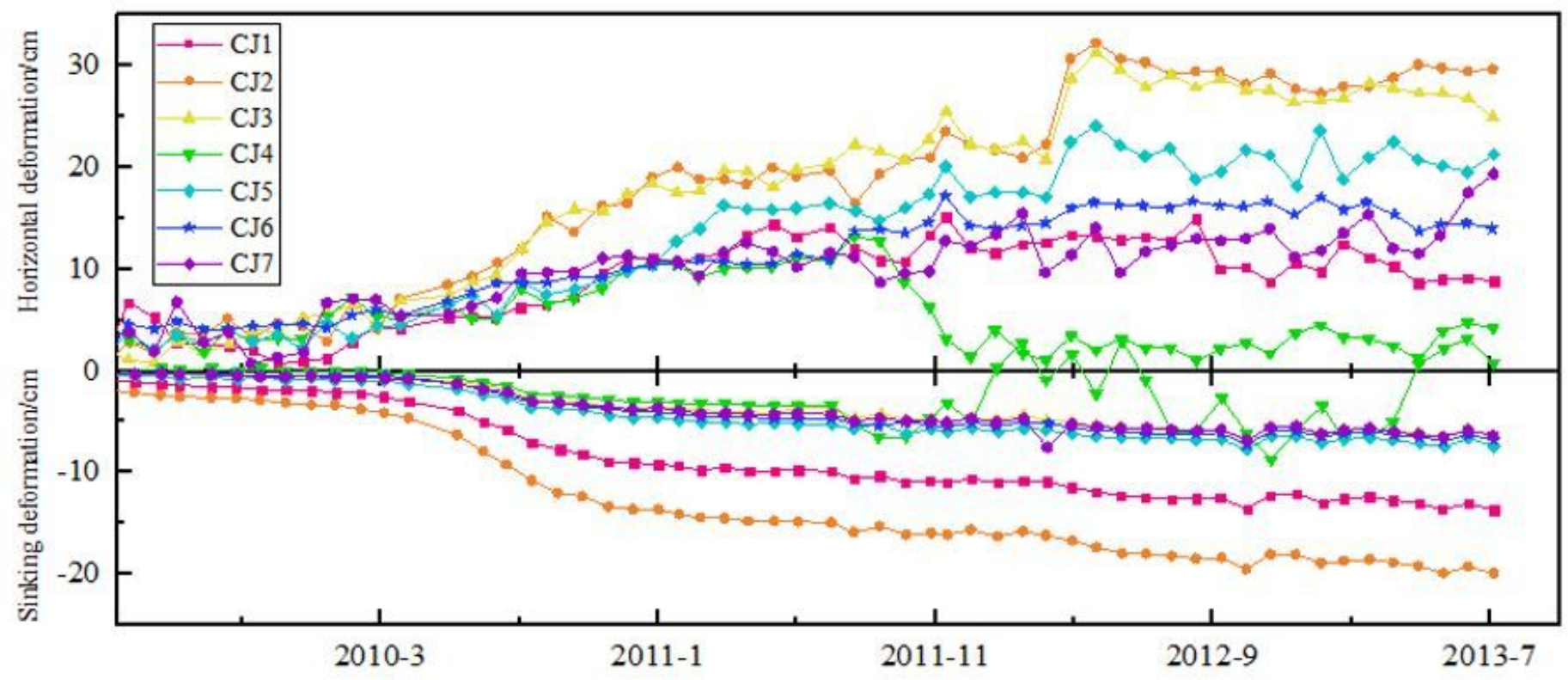

Figure 13

Cumulative deformation map of measuring points near new auxiliary shaft 


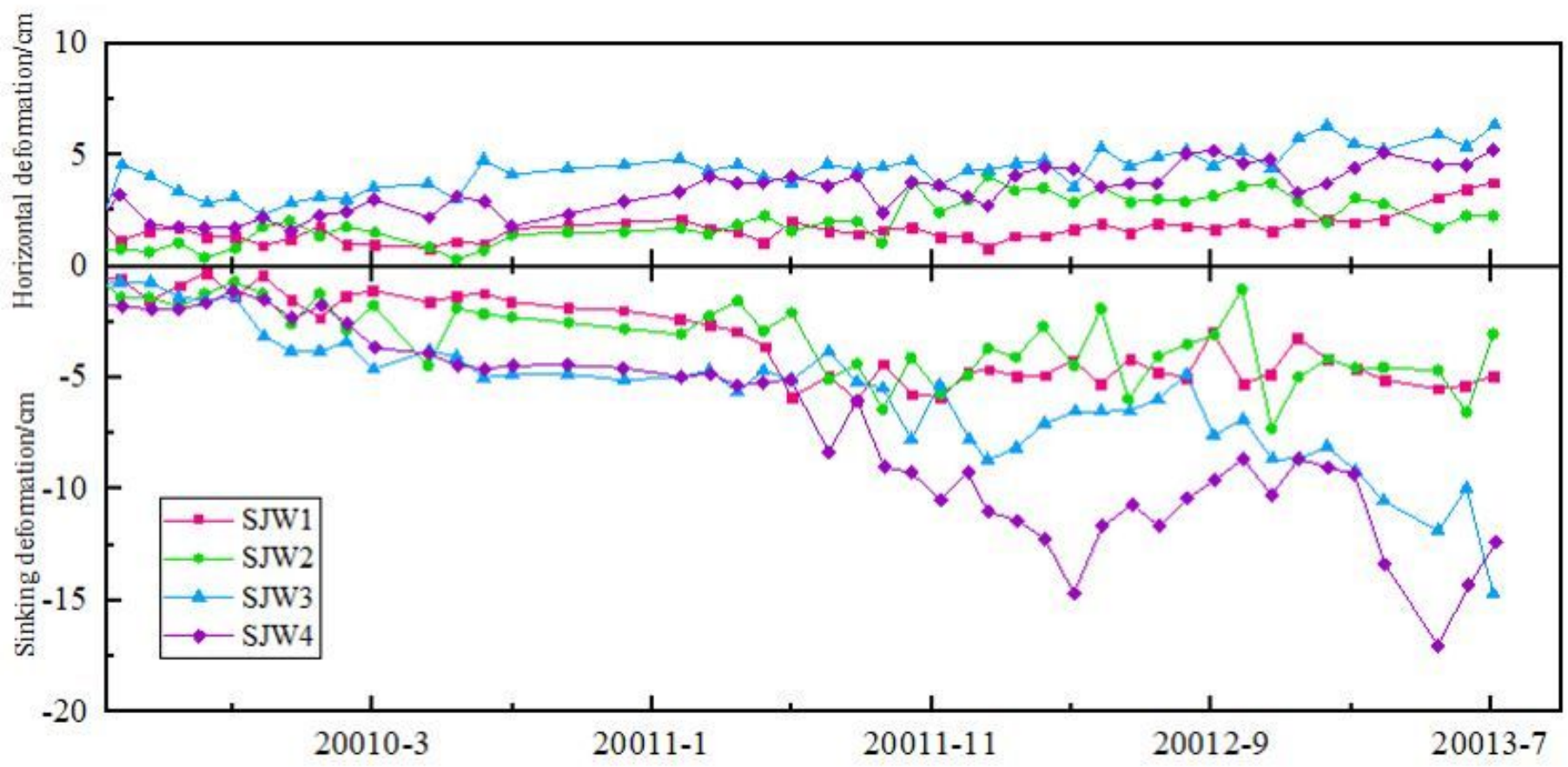

Figure 14

Cumulative deformation map of measuring points near Shijiawan village

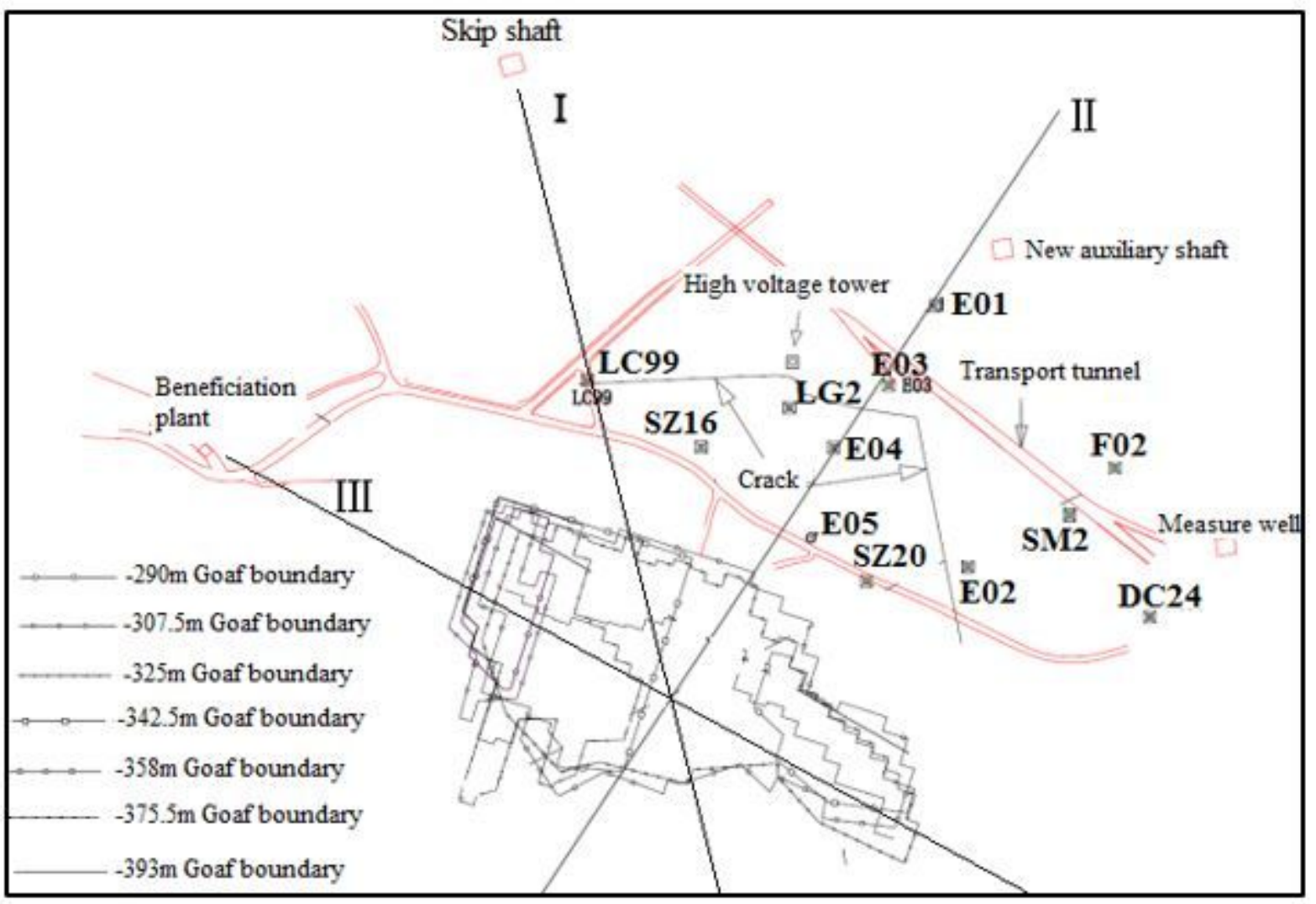

Figure 15 


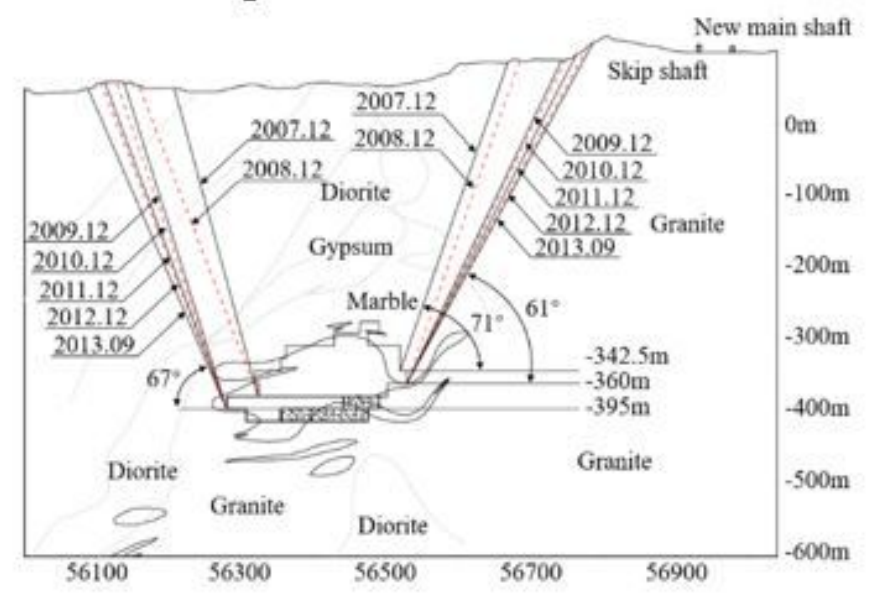

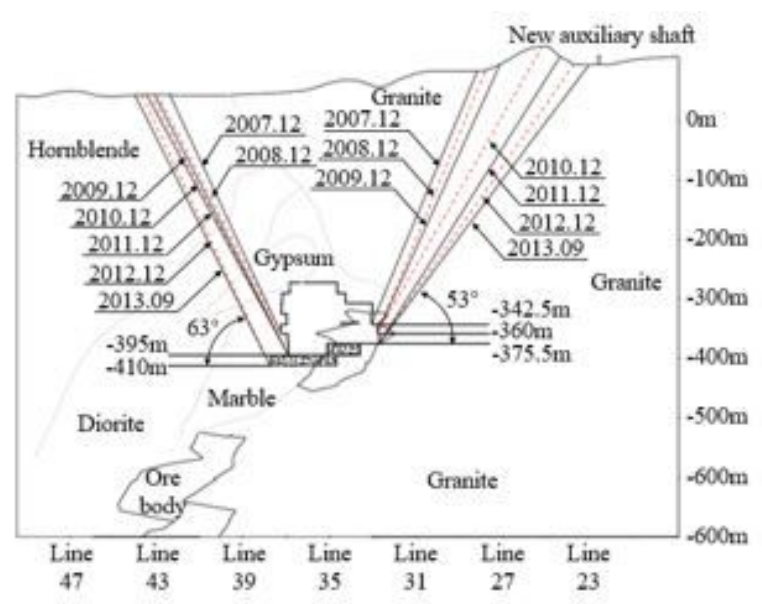

(b) Movement angle of section II

(a) Movement angle of section I

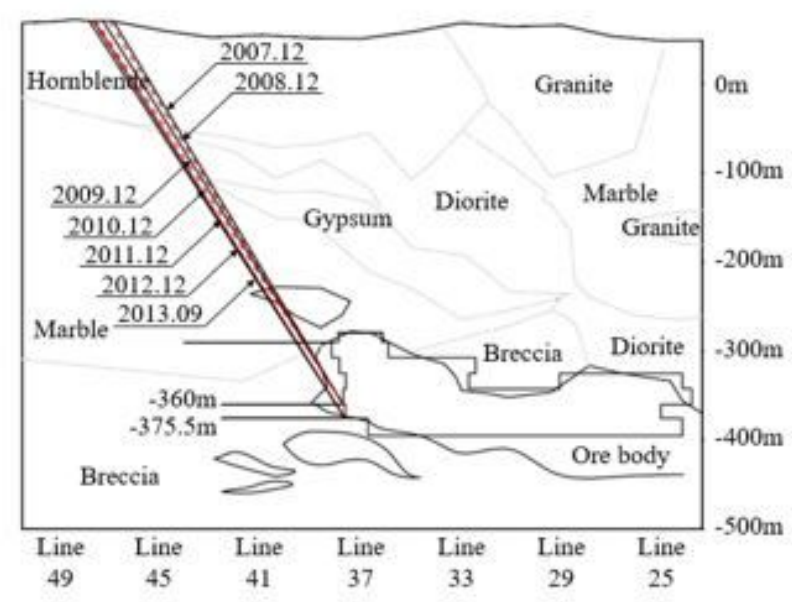

(c) Movement angle of section III

\section{Figure 16}

Variation law of movement angle of each section 


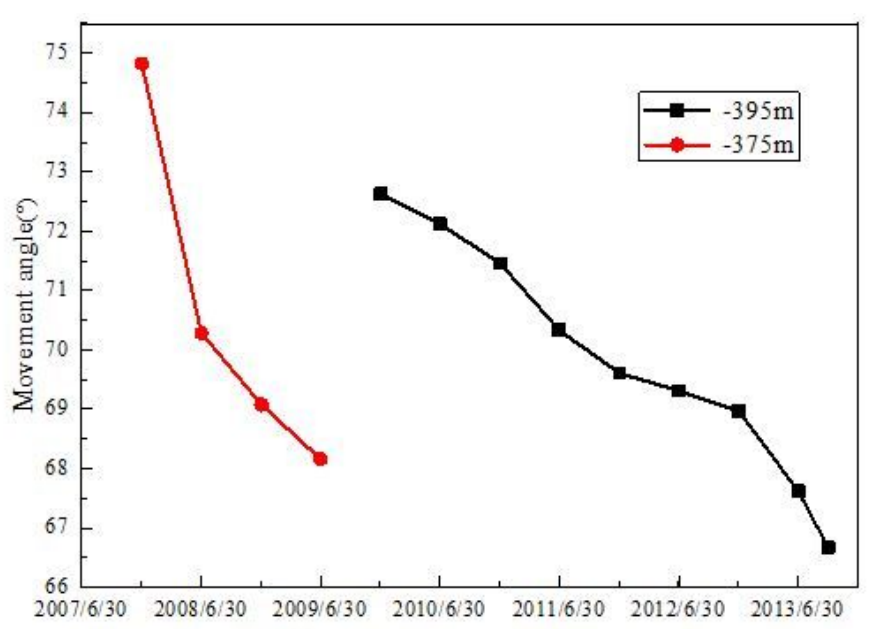

(a) Change of hanging wall movement angle

\section{Figure 17}

Change of movement angle with time in section I

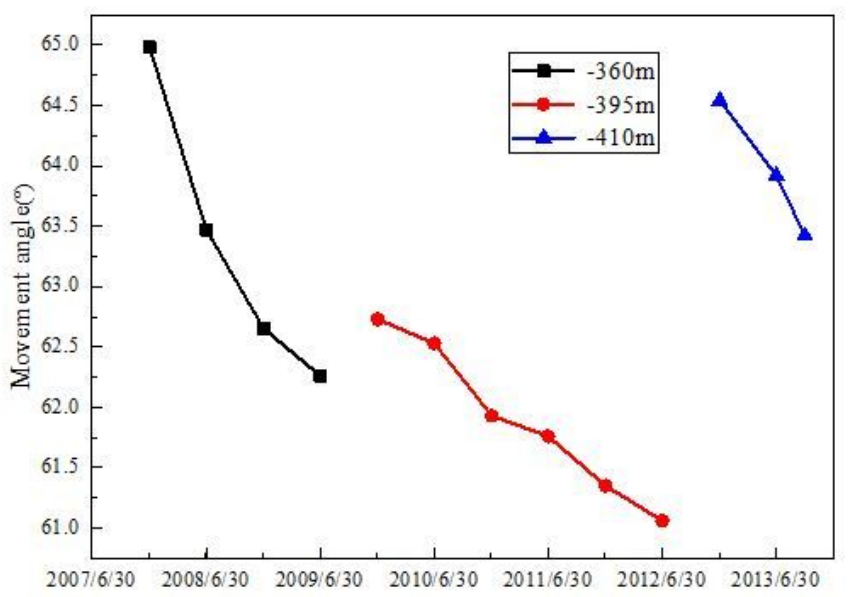

(a) Change of hanging wall movement angle

\section{Figure 18}

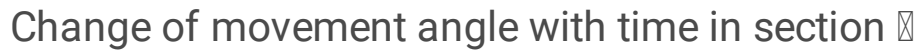

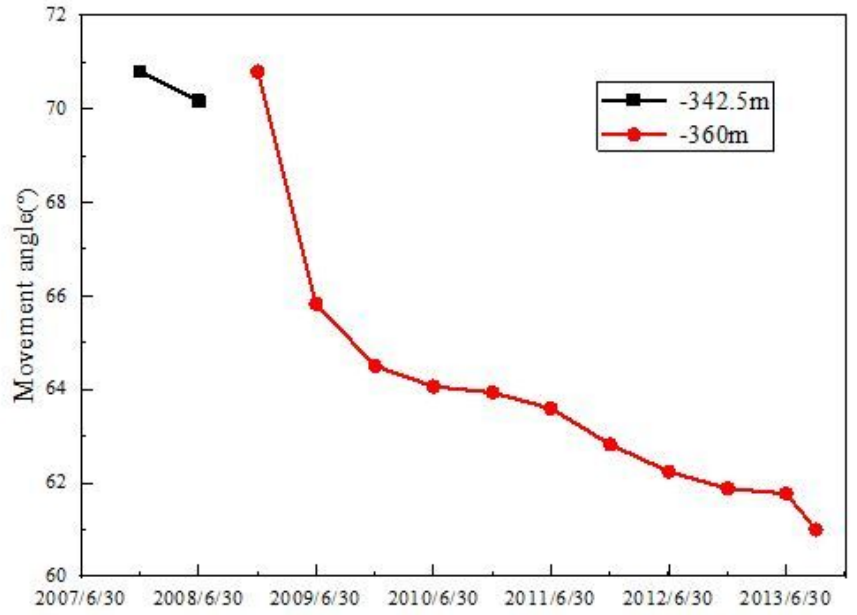

(b) Change of footwall movement angle

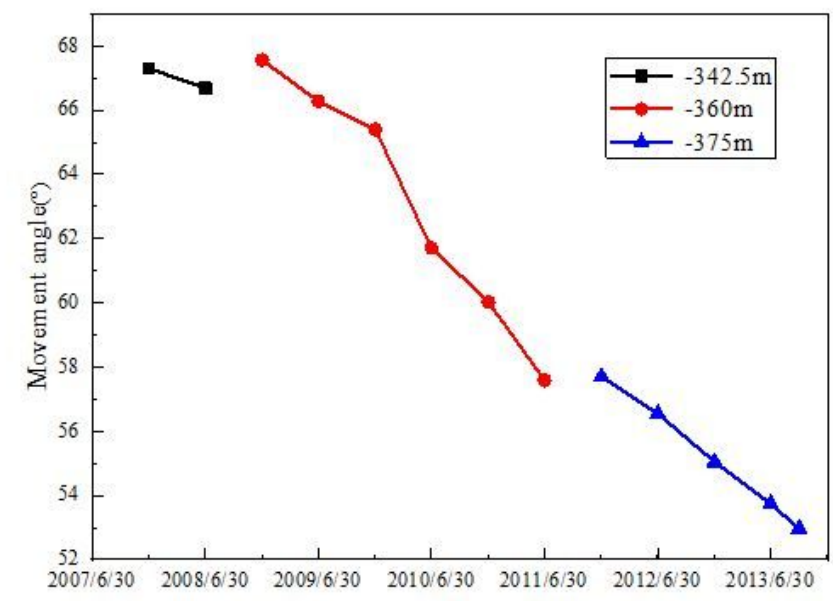

(b) Change of footwall movement angle 


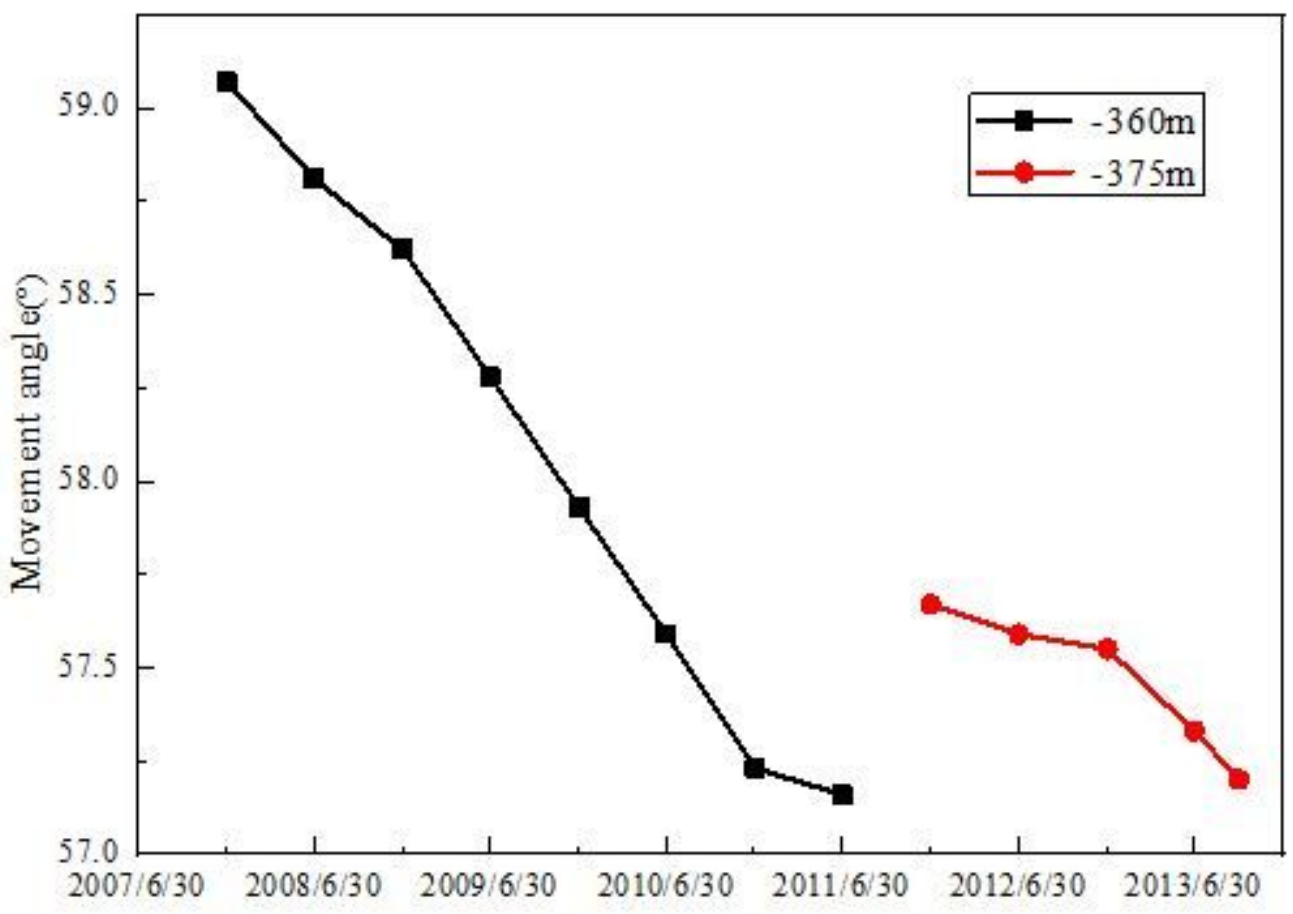

Figure 19

Change of movement angle with time in section $\nabla$ west end
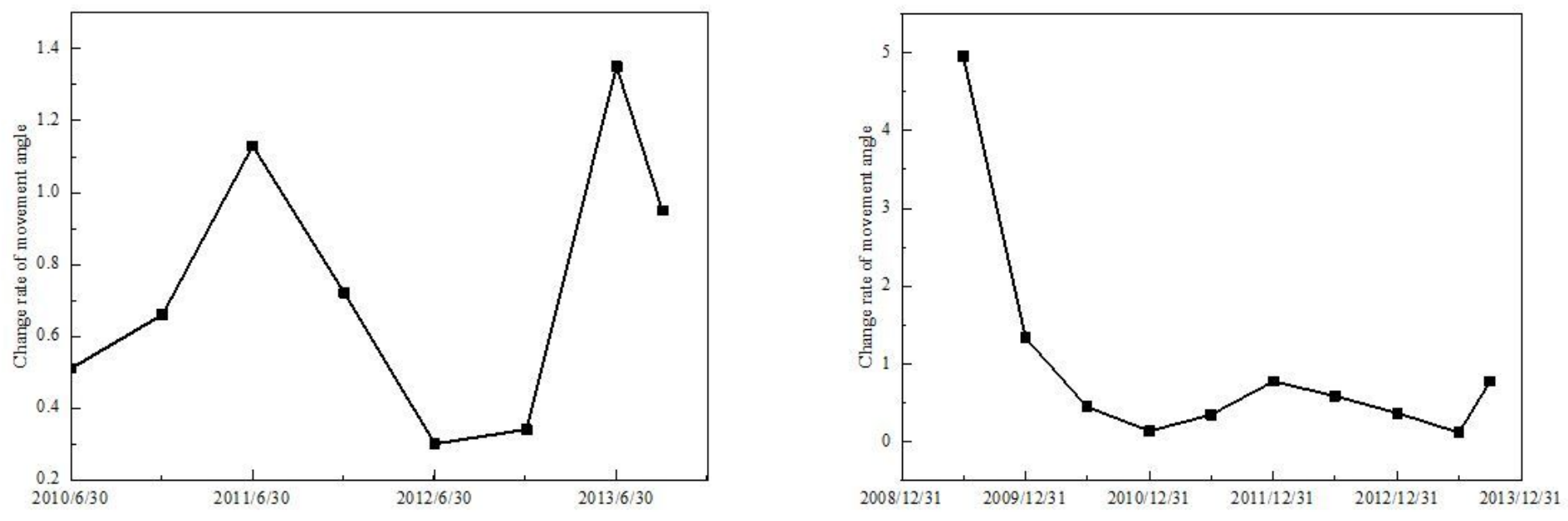

(a) Change rate of hanging wall movement angle (b) Change rate of footwall movement angle

Figure 20

Change rate of movement angle in section I 


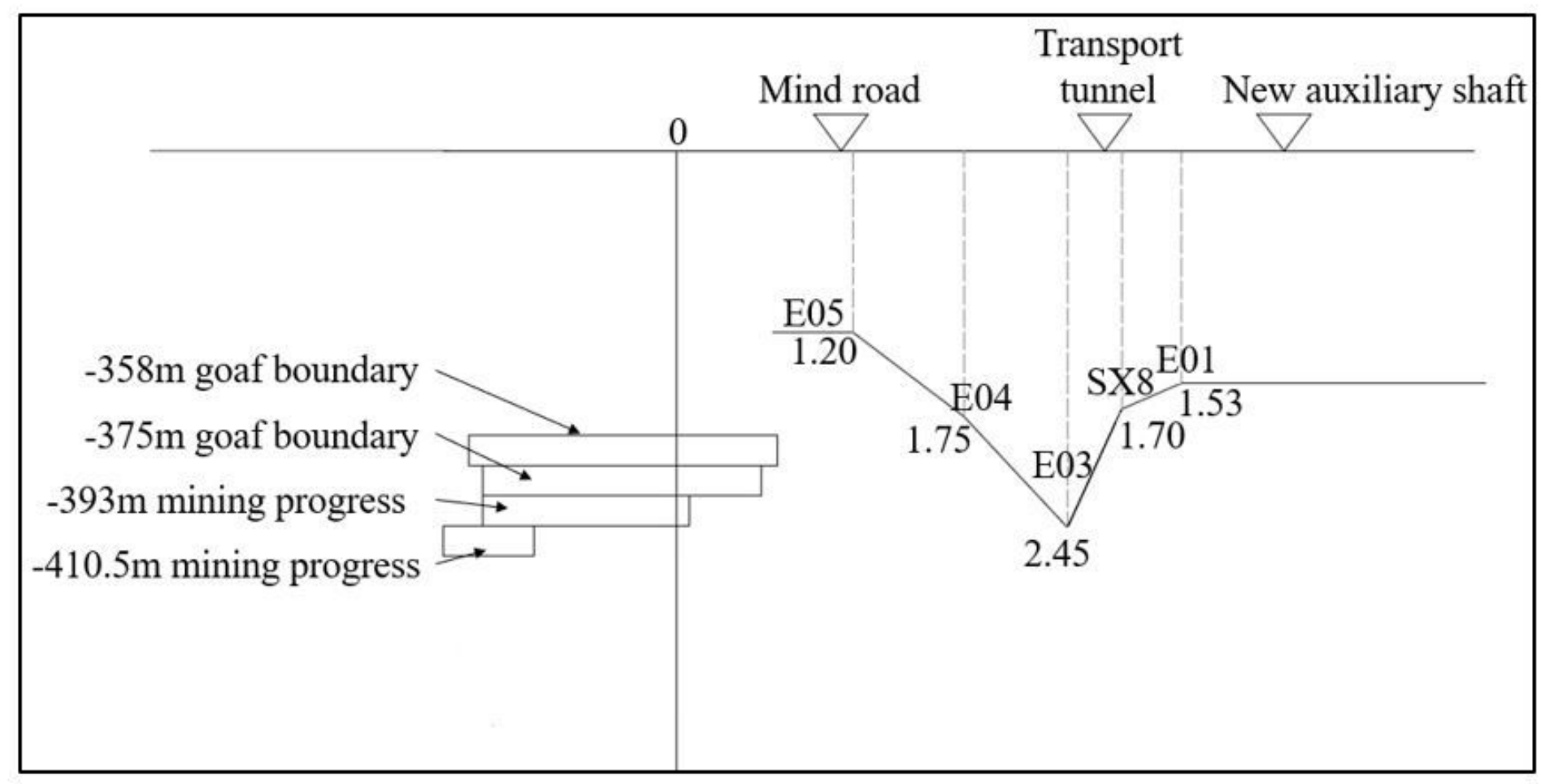

Figure 21

Distribution of the ratio of horizontal deformation to subsidence deformation in section $\mathbb{Q}$

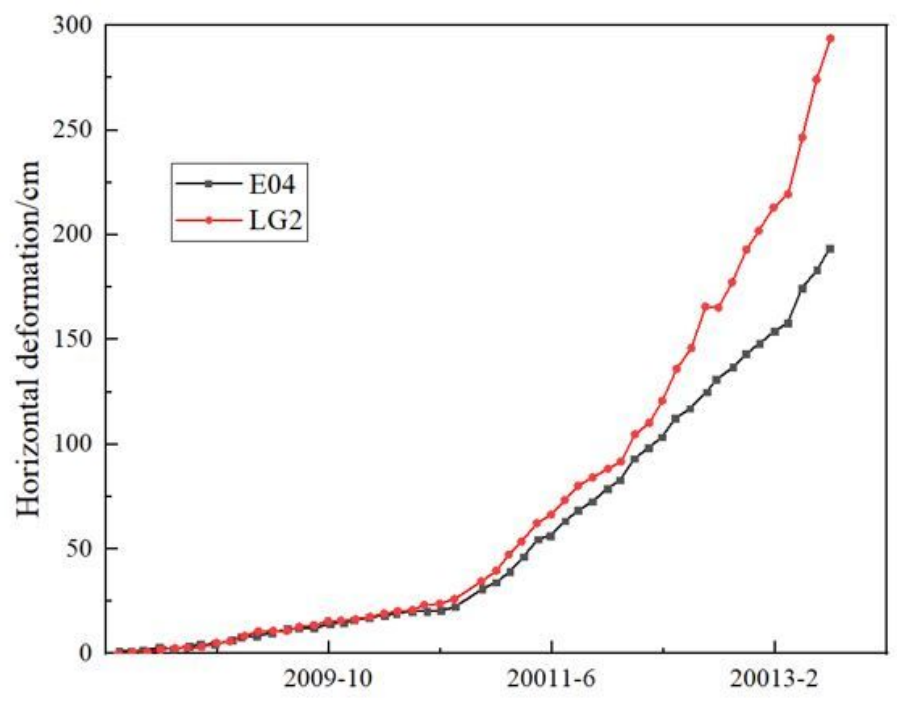

(a) Horizontal deformation

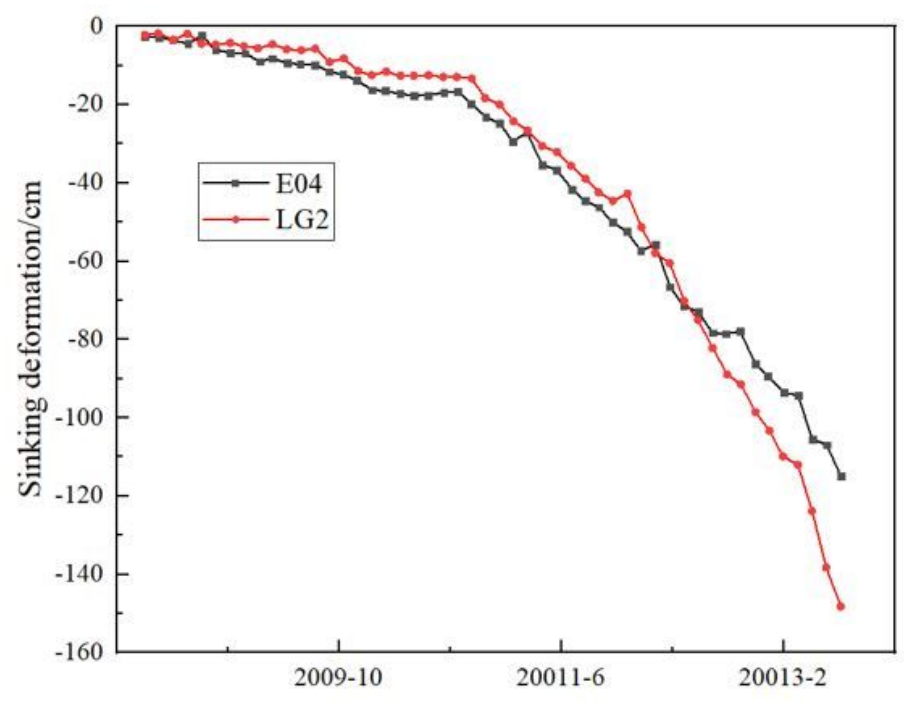

(b)Sinking deformation

Figure 22

Displacement curve of LG2 and E04 


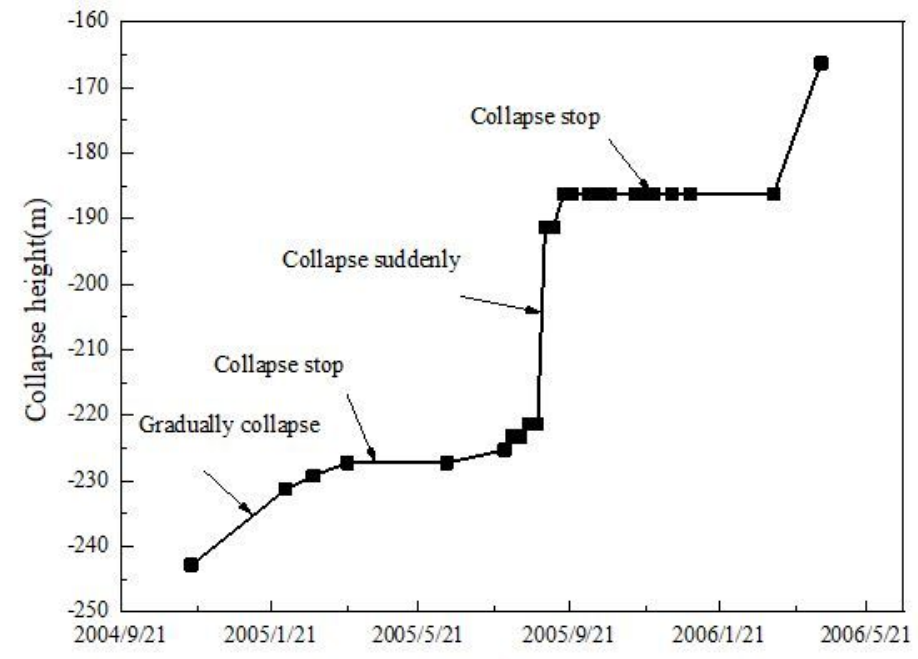

(a)ZK1

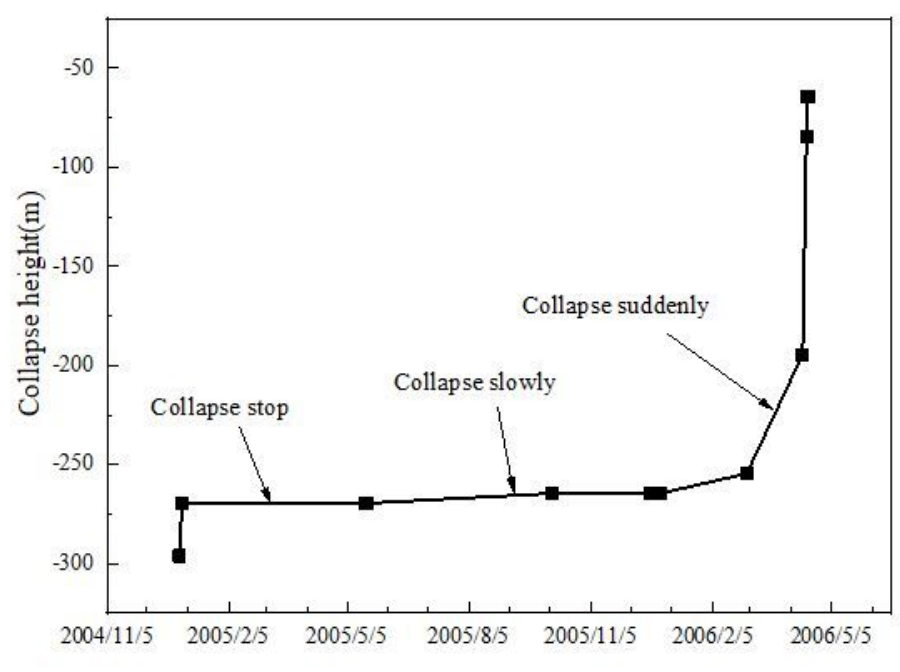

(b)ZK2

Figure 23

Monitoring results curve

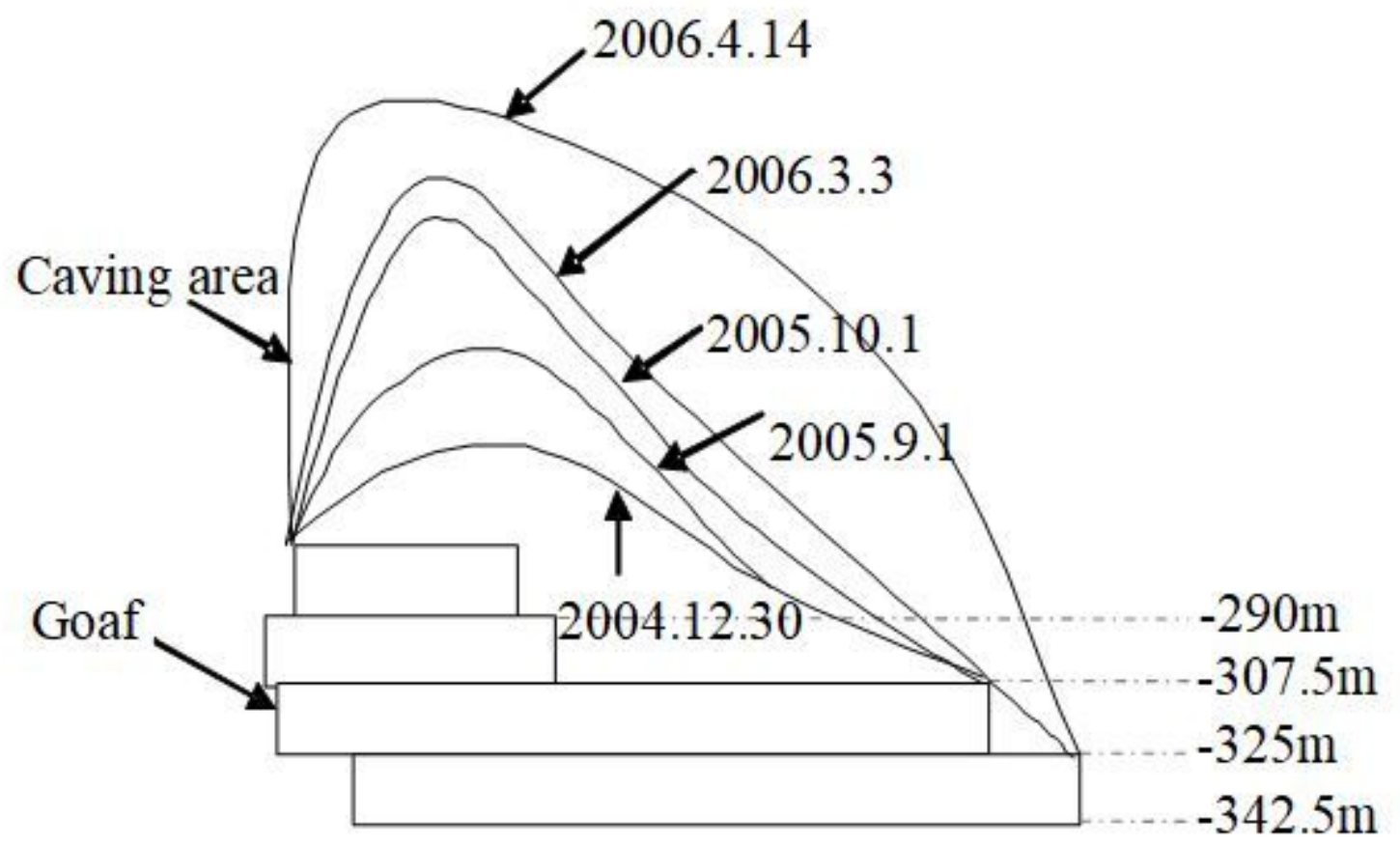

\section{Figure 24}

Opposite relationship diagram of gob and caving 


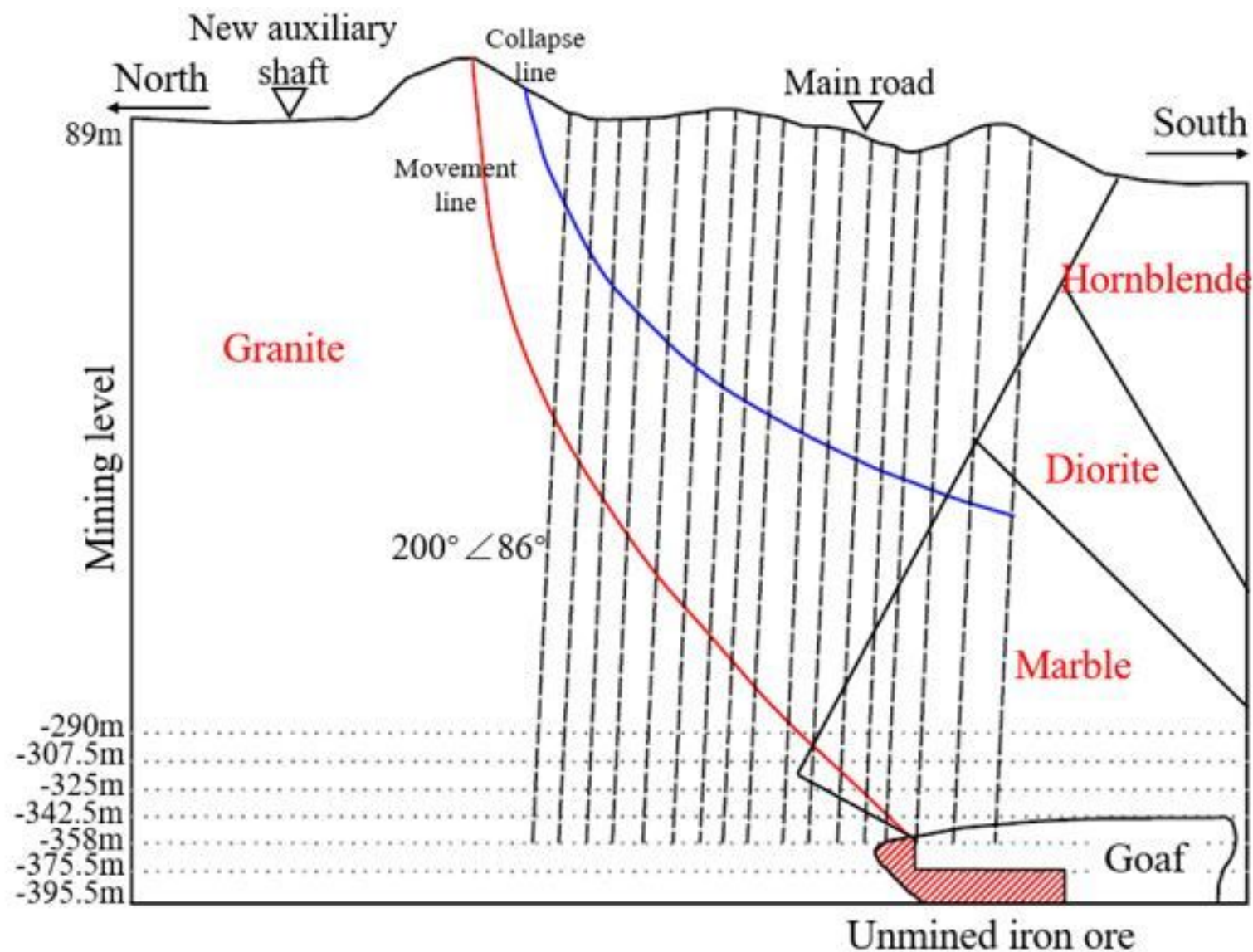

Figure 25

Geomechanical model of Chengchao Iron Mine 


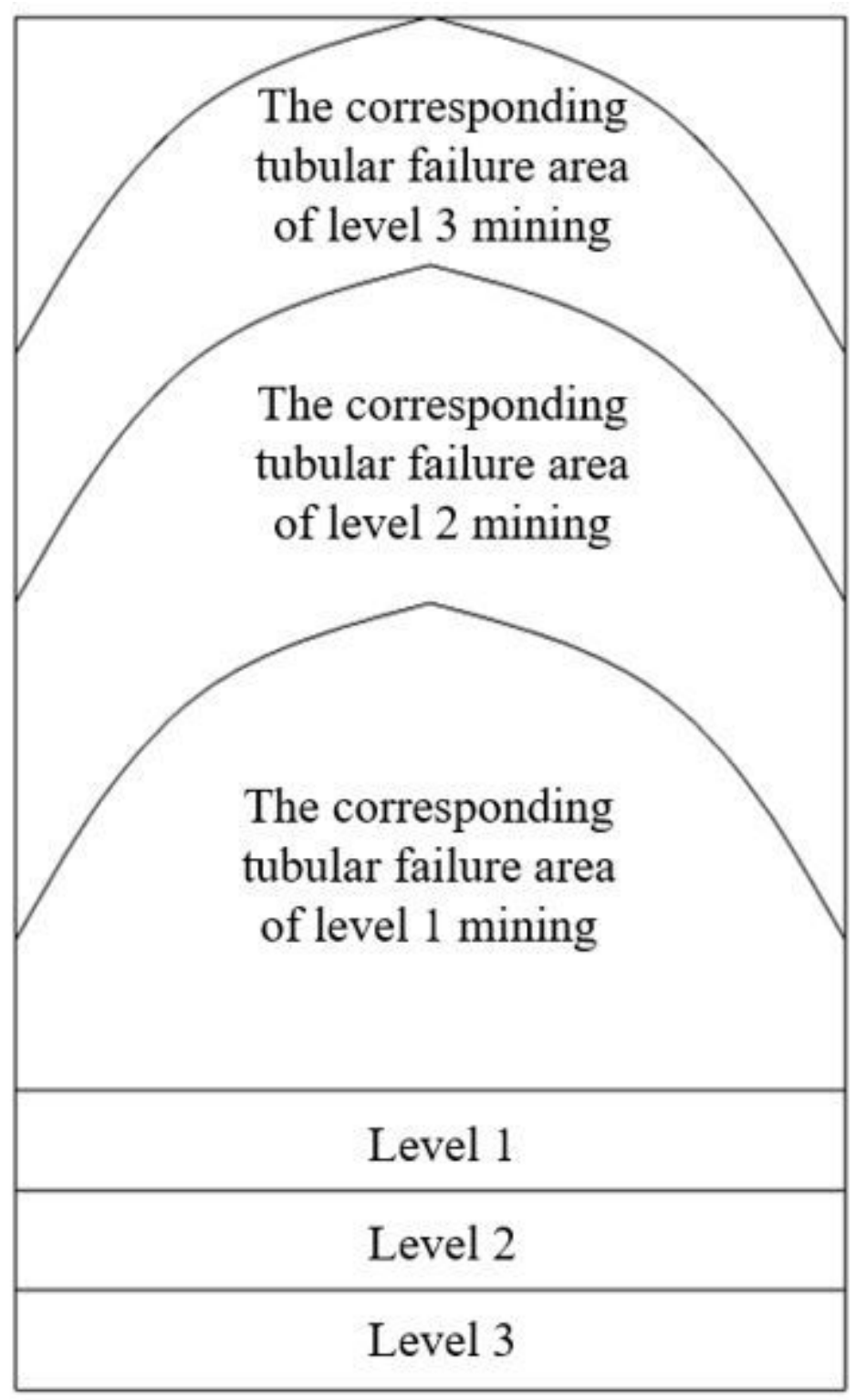

Figure 26

Schematic diagram of the cylindrical collapse process 

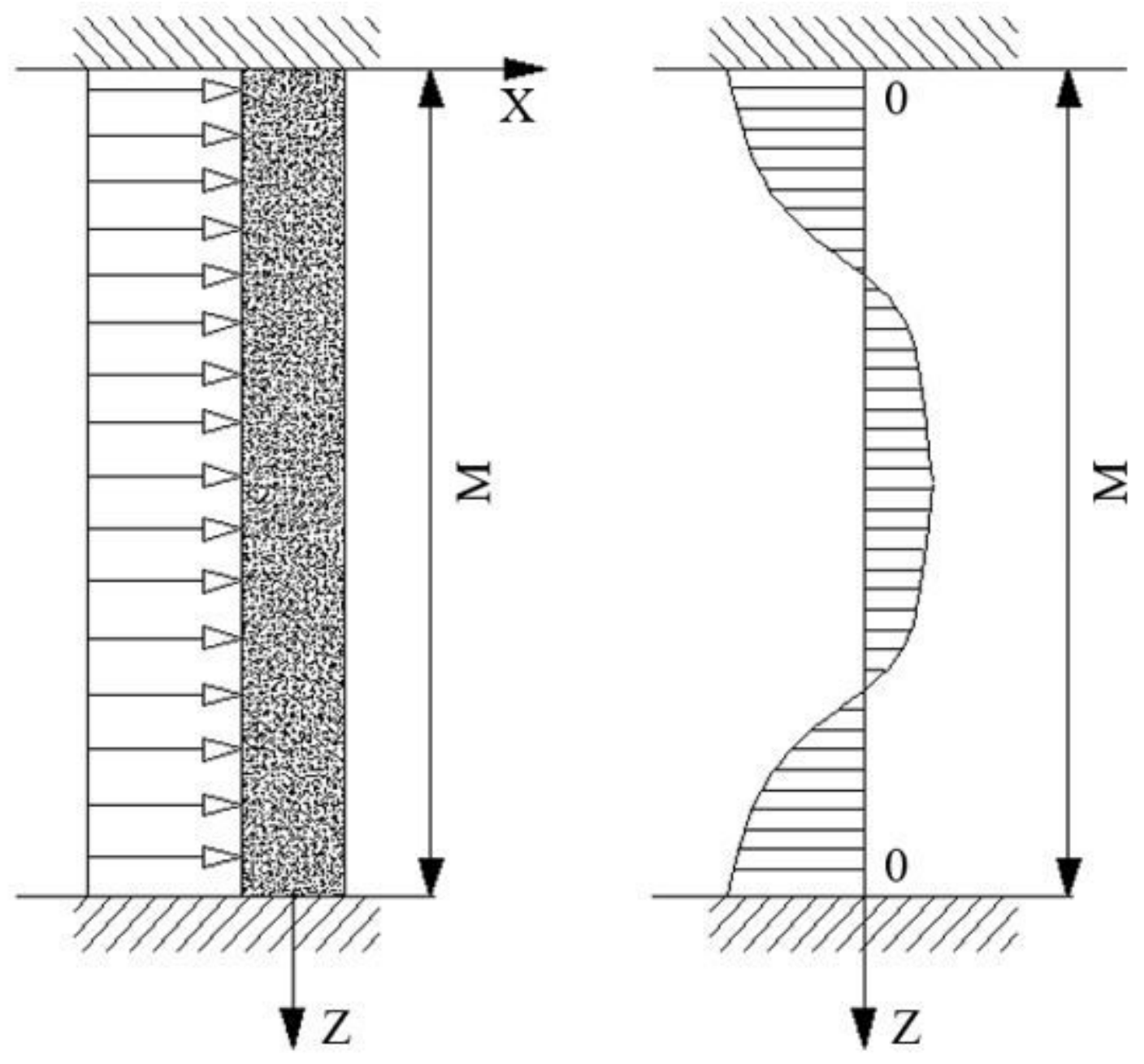

Figure 27

Schematic diagram of rock pillar mechanical model 


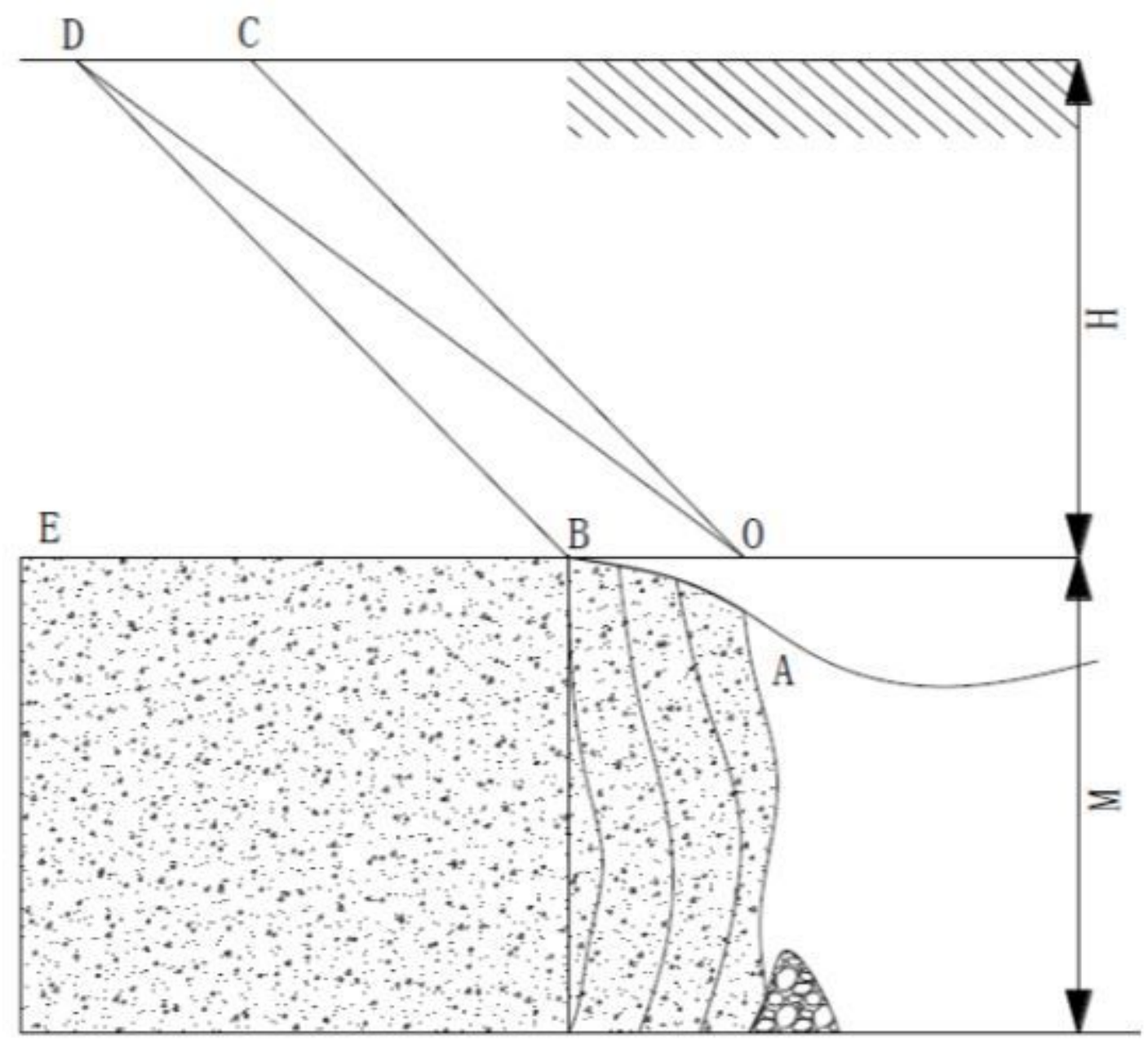

Figure 28

Schematic diagram of pillar failure 


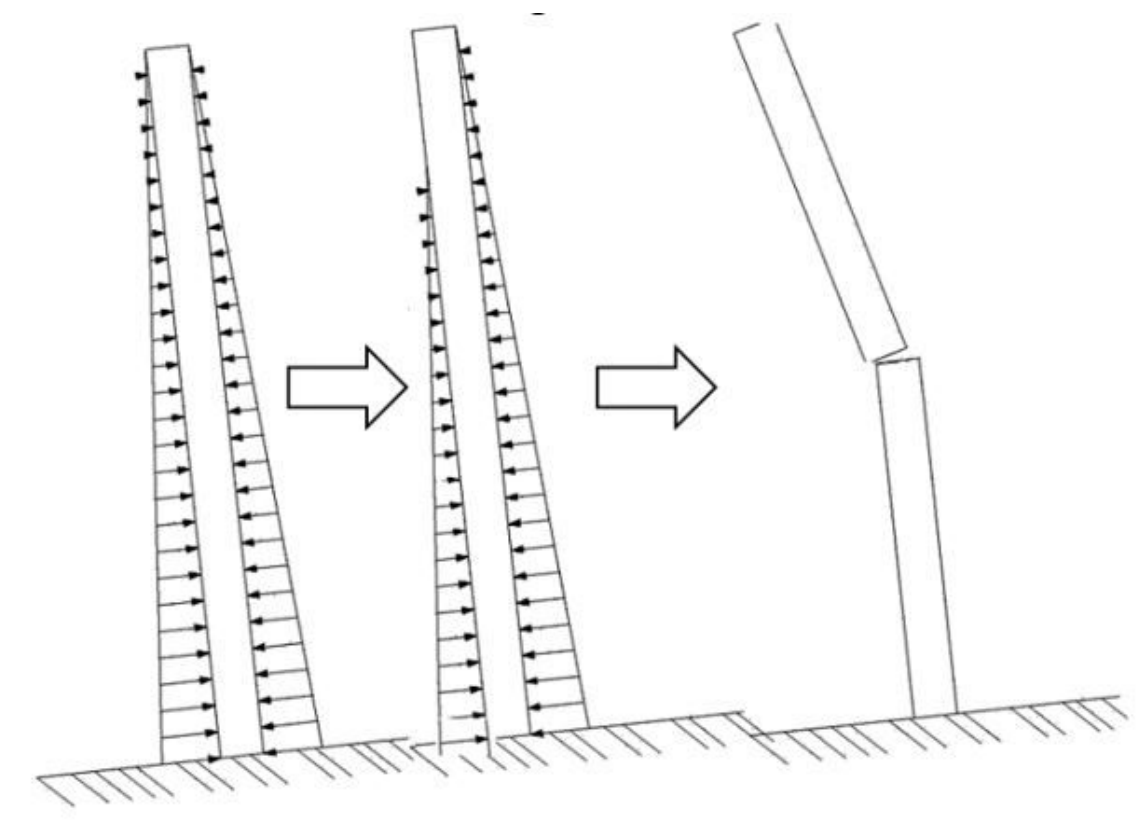

(a)Before surface collapse (b)After surface collapse (c)Bending fracture failure occurred

Figure 29

Stress and failure diagram of cantilever beam
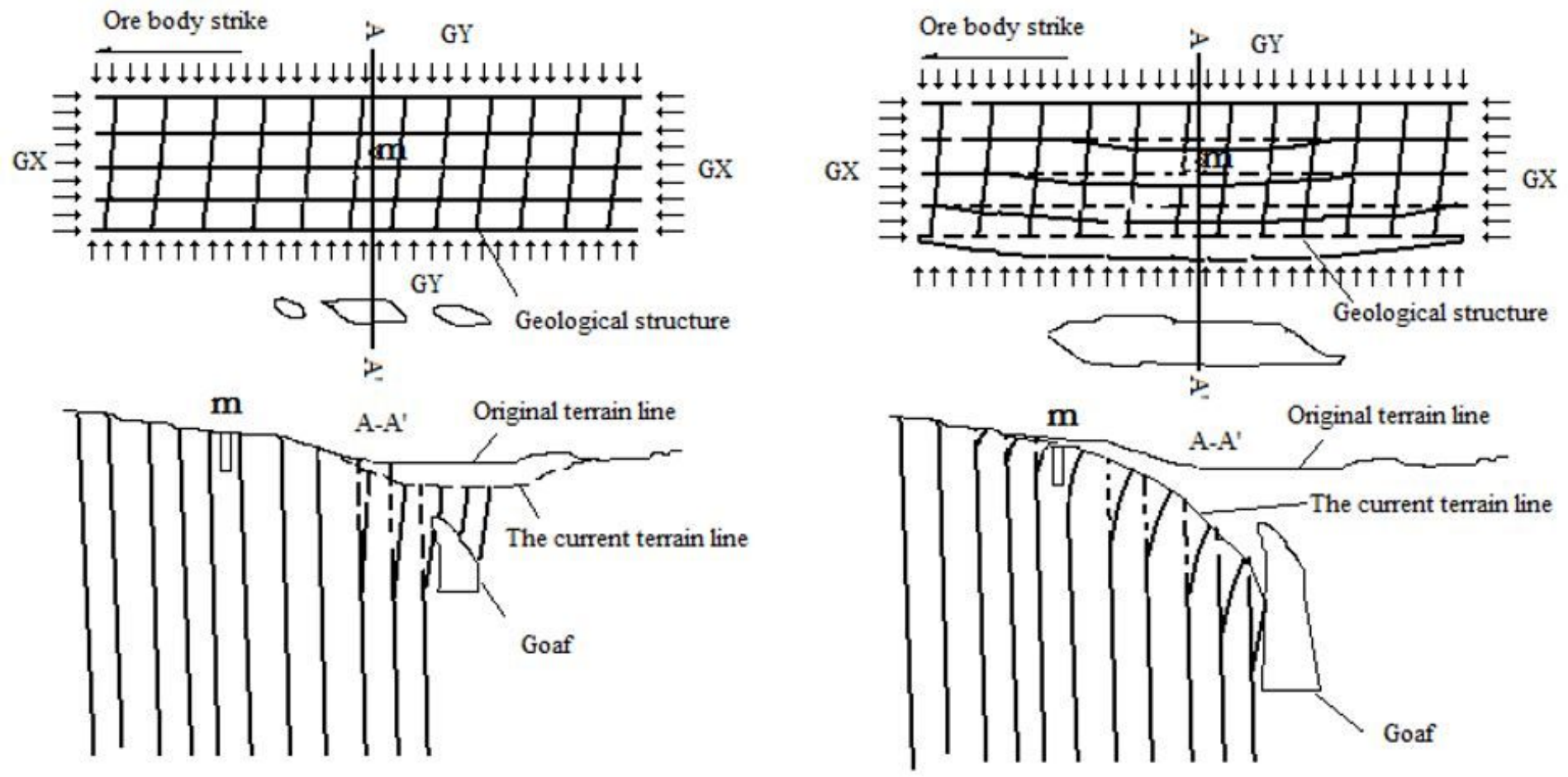

(a)One stage

(b)Two stage

Figure 30 
Schematic diagram of surface deformation process under horizontal stress

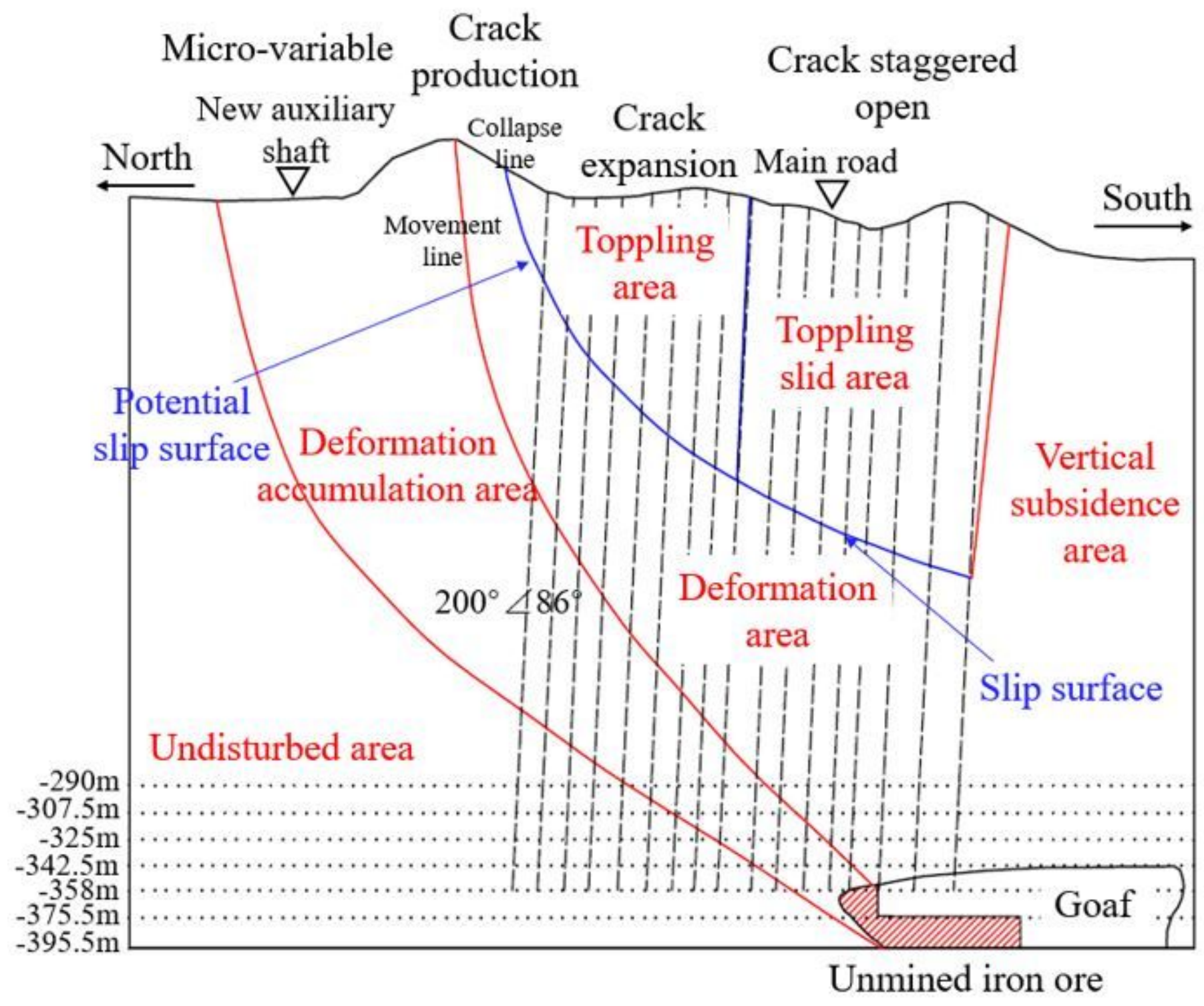

Figure 31

Schematic diagram of strata movement zoning 


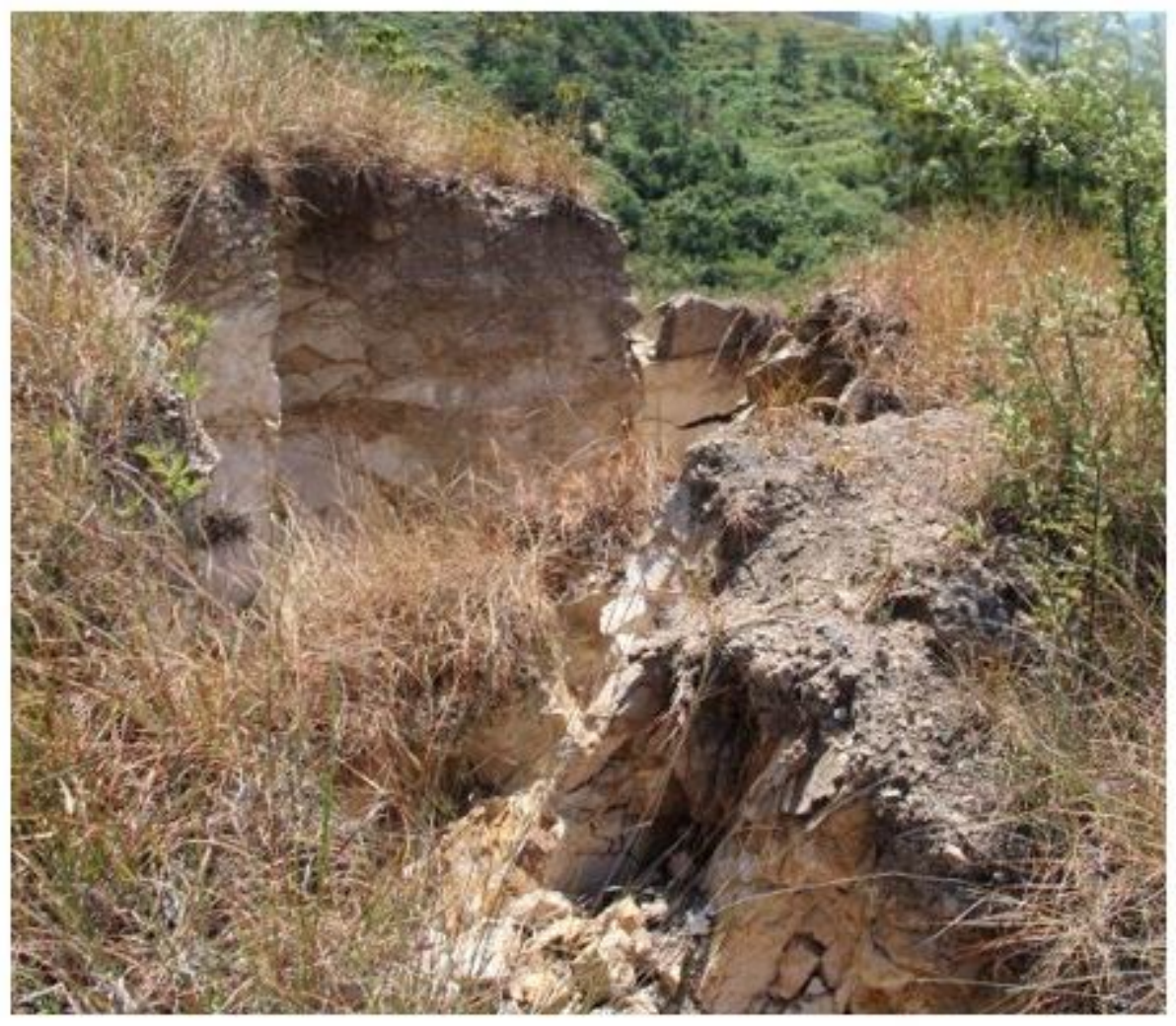

\section{Figure 32}

Large cracks at high voltage tower

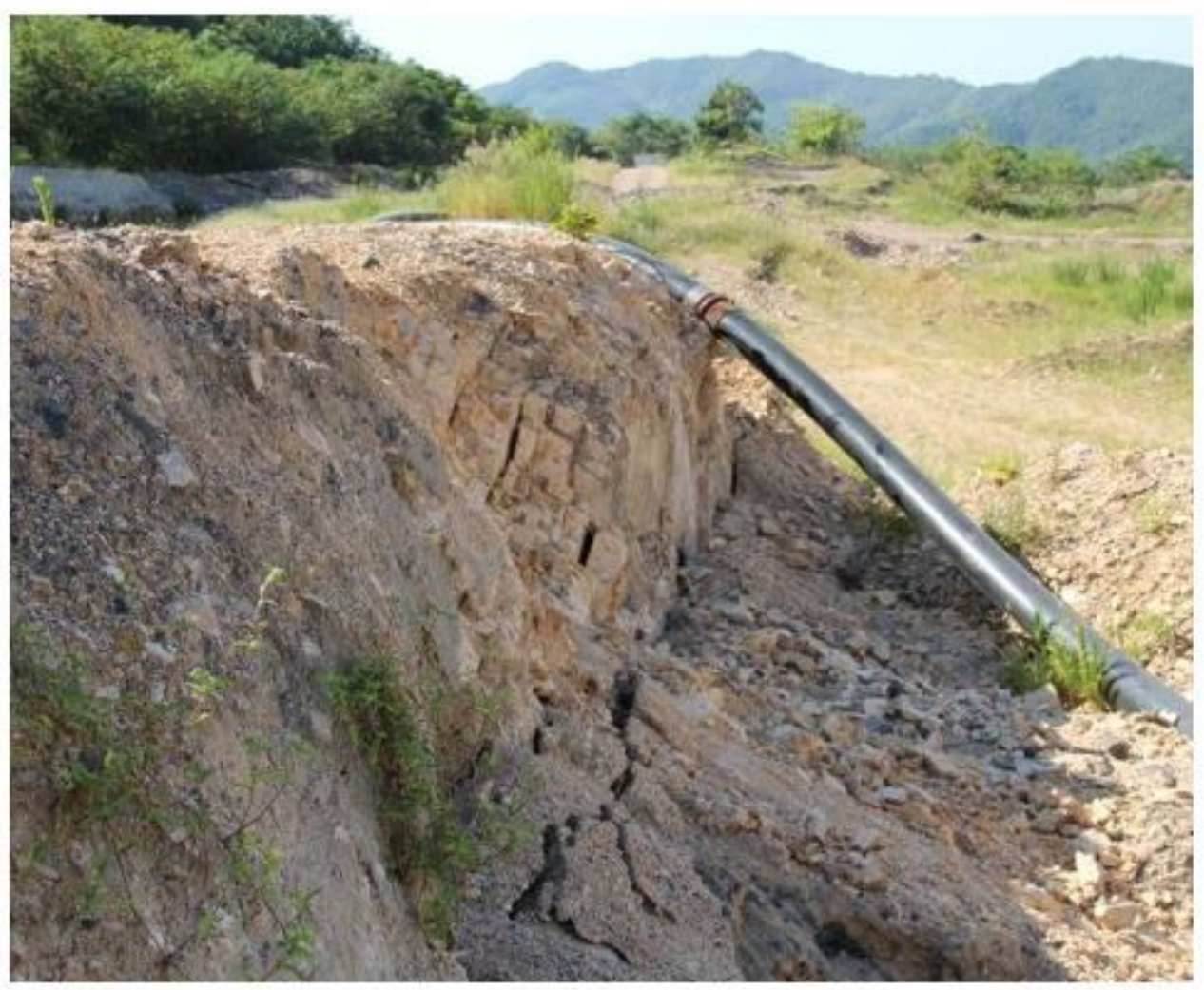

Figure 33 
Fractures at mine road
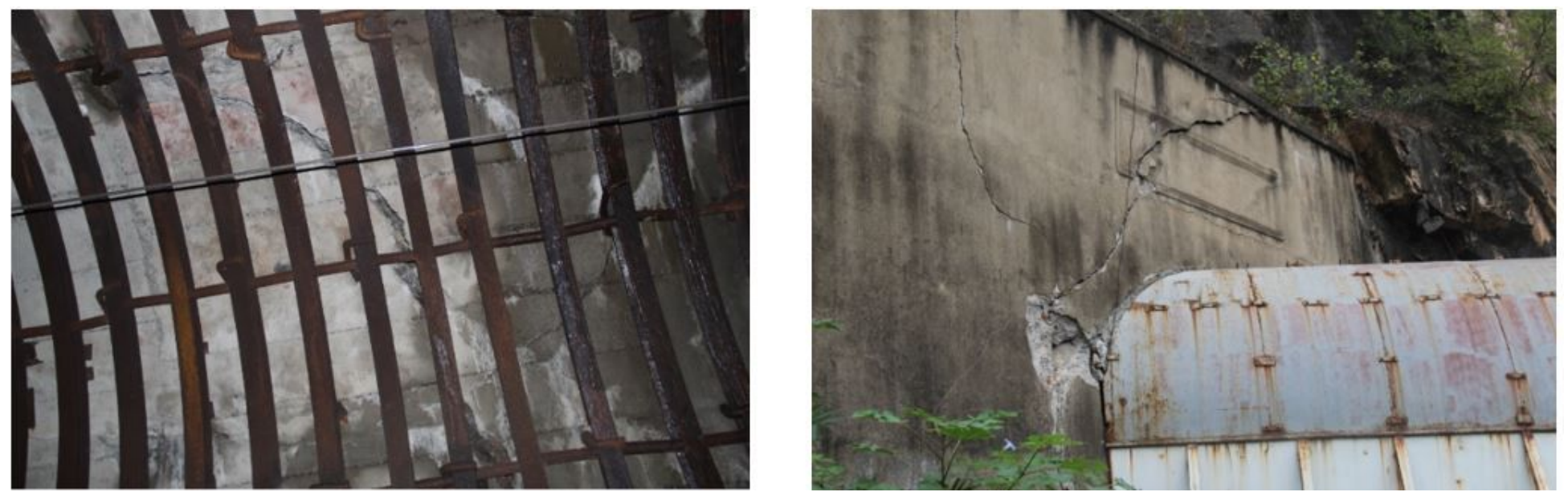

Figure 34

Cracks at transport tunnels 